\title{
Role of twinning on the stress and strain behaviors during reverse loading in rolled magnesium alloy sheets
}

\section{$\operatorname{AUTHOR}(S)$ :}

Hama, Takayuki; Suzuki, Tomotaka; Hatakeyama, Shinichi; Fujimoto, Hitoshi; Takuda, Hirohiko

\section{CITATION:}

Hama, Takayuki ... [et al]. Role of twinning on the stress and strain behaviors during reverse loading in rolled magnesium alloy sheets. Materials Science and Engineering: A 2018, 725: 8-18

\section{ISSUE DATE:}

2018-05-16

URL:

http://hdl.handle.net/2433/235738

\section{RIGHT:}

(c) 2018. This manuscript version is made available under the CC-BY-NC-ND 4.0 license

http://creativecommons.org/licenses/by-nc-nd/4.0/; The full-text file will be made open to the public on 16 May 2020 in accordance with publisher's 'Terms and Conditions for Self-Archiving'; この論文は出版社版でありません。引用の際に は出版社版をご確認じ利用ください。; This is not the published version. Please cite only the published version. 
Role of twinning on the stress and strain behaviors during reverse loading in rolled magnesium alloy sheets

Takayuki HAMA

Tomotaka SUZUKI

Shinichi HATAKEYAMA

Hitoshi FUJIMOTO

Hirohiko TAKUDA

Department of Energy Science and Technology, Kyoto University

Yoshida-Honmachi, Sakyo-ku, Kyoto 606-8501, Japan

Corresponding Author: Takayuki HAMA

e-mail: hama@energy.kyoto-u.ac.jp

Keywords: Magnesium alloy sheet, Twinning, Detwinning, Reverse loading, Crystal plasticity finite-element analysis, Lankford value

Declarations of interest: none 


\section{Abstract}

Reverse loading from compression to tension was performed on a rolled AZ31 magnesium alloy sheet to systematically study the effects of twinning and detwinning on the stress and strain behaviors after stress reversal. A crystal plasticity finite-element simulation was also conducted to study the underlying deformation mechanisms. This paper consists of the following three findings. (1) A sigmoidal curve occurred irrespective of compressive strain, while the sigmoidal curve became less pronounced as the compressive strain increased. The simulation results showed that the shift from detwinning-dominated to slip-dominated deformation became more gradual as the compressive strain increased; thus, the sigmoidal curve became less pronounced. (2) The yield stress after stress reversal increased when the sheet was annealed prior to reverse loading. The simulation results suggested that one of the mechanisms was that the residual stresses generated during compression acted as back stresses to detwinning activity; thus, the yield stress was increased by removing the residual stresses by annealing. (3) The Lankford value after stress reversal was relatively small and further decreased during the first work-hardening stage, whereas it increased during the second stage. The simulation results indicated that the thickness strain was composed of both slip and detwinning activities in the first stage, while only slip activity contributed toward the thickness strain in the second stage, which resulted in the difference in the evolution of the Lankford value between the first and second stages.

\section{Introduction}

Magnesium alloy sheets have the potential to expedite the lightening of vehicles because of their high specific strength and low density. $\mathrm{Mg}$ alloy sheets usually adopt a hexagonal close-packed (hcp) structure, whose critical resolved shear stresses (CRSSes) differ depending on the slip plane. Moreover, deformation twinning with polar character is easily activated. These anisotropies in the crystal scale eventually yield characteristic macroscopic deformation, including asymmetry between tension and compression [1-3], strain-path dependency [4-6], and low formability at room temperature [7,8]. In addition, characteristic deformation is further emphasized by the basal texture developed in rolled sheets that are generally used as structural components. These characteristic deformation behaviors complicate the forming of $\mathrm{Mg}$ alloy sheets, hindering their application to structural components. Therefore, over the past decade, many studies have been reported in an attempt to comprehensively understand the underlying mechanisms of deformation behaviors and to expand the application of $\mathrm{Mg}$ 
alloy sheets [1-10].

It has been established that twinning is reversible when it is subjected to reverse loading, so-called detwinning, and that detwinning and twinning both play critical roles in the plastic deformation of $\mathrm{Mg}$ alloy sheets. For example, a sigmoidal stress-strain curve appears when rolled $\mathrm{Mg}$ alloy sheets with strong basal texture experience reverse loading, going from compression to tension. This behavior has been studied both experimentally $[1,2,11]$ and theoretically $[6,12,13]$, and it has been established that detwinning is primarily responsible for this behavior. Detwinning activity is dominant in the initial tension stage (detwinning-dominated deformation), but after detwinning activity decreases, slip activities are dominant in the latter stage (slip-dominated deformation). A similar curve is observed in cast $\mathrm{Mg}$ alloy sheets with nearly random crystal orientations [14]. Recently, Hama et al. [15] reported that the sigmoidal curve became less pronounced as the compressive strain prior to stress reversal increased. Although the mechanism of this behavior was briefly discussed [15, 16], it is not understood in detail.

It is well-known that the yield stress in tension following compression is quite small, due to a strong Bauschinger effect. Usually, detwinning can be activated under a lower stress than twinning because the nucleation of twins is not required during detwinning [17], and a back stress can assist in its activation [18-20]. For instance, Wu et al. [18] measured the internal strain evolution during compression followed by tension using in situ neutron diffraction and showed that the sign of the internal stress in the twinned region changed upon unloading, assisting detwinning activity. Consistent with these results, Park et al. [19] reported that detwinning activity in the subsequent tension was retarded by annealing the sample after compression. Similar results were also reported in multiple studies by Xin et al. [21, 22]. Cui et al. [23] recently discussed the effect of back stress on detwinning activity in detail. However, this discussion was based on a rather a simple stress analysis. Thus, the detailed role of back stress is not well understood and its underlying mechanisms remain to be conclusively determined.

Strain behavior is also affected by twinning. Based on the Schmid factor, Brown et al. [24] estimated that twinning accounted for $61 \%$ of the plastic deformation in the initial stage of in-plane compression of rolled AZ31 Mg alloy plates. Chen et al. [25] recently performed a similar analysis and estimated that twinning constituted approximately $80 \%$ of the plastic deformation during compression along the extruded direction of an extruded $\mathrm{Mg}$ alloy. It was hypothesized that twinning would primarily affect the thickness strain in rolled $\mathrm{Mg}$ alloy sheets because of its strong basal texture. Steglich et al. [26] measured the evolution of the Lankford value of a rolled $\mathrm{Mg}$ alloy 
sheet and observed that it was significantly smaller under compression than under tension. This was presumably because of larger twinning activity under compression. These results suggest that detwinning would also affect the thickness strain during reverse loading from compression to tension. More recently, Hama et al. [6] reported that the Lankford value under tension was significantly smaller in a pre-compressed sheet than that in a virgin sheet, consistent with the abovementioned hypothesis. If the small Lankford value in the pre-compressed sheet is due to detwinning activity, it is presumed that evolution of the Lankford value, i.e. the evolution of thickness strain, would be highly correlated with detwinning activity. However, the Lankford value was measured at a strain of only $10 \%$ in the previous study [6] and its detailed mechanism is not yet understood. As described above, although characteristic twinning and detwinning activities have been studied extensively [18, 19, 21, 22, 23, 27-29] with some investigations focused on the effects on mechanical properties [6, 20, 24-26, 30-32], the effects of twinning and detwinning on the macroscopic stress and strain behaviors have not been sufficiently examined.

Crystal plasticity models can correlate macroscopic deformation with mesoscopic deformation at the grain level and have been used to understand the underlying mechanism of deformation behavior in $\mathrm{Mg}$ alloys [6, 12, 13, 14, 33-39]. Many of the previous crystal plasticity analyses on deformation behavior of $\mathrm{Mg}$ alloys focused on work-hardening behaviors. However, crystal plasticity models can also be used to examine the increase in the yield stress after stress reversal by annealing, and the role of back stresses investigated more quantitatively. However, to the best of our knowledge, such a study has not yet been conducted. Moreover, crystal plasticity analysis has not widely been used to discuss strain behavior, including the Lankford value. Wang et al. [40] predicted asymmetry in the Lankford value evolution between tension and compression and discussed its underlying mechanism. However, the evolution of the Lankford value during reverse loading has not been examined experimentally or theoretically. Hama et al. [6] reproduced the Lankford values under tension in a pre-compressed and virgin sheet fairly well using a crystal plasticity finite-element method and discussed the related deformation mechanism. However, the strain evolution was not examined, and the correlation between twinning and detwinning activities and the Lankford value was not discussed.

In this study, stress and strain behaviors upon reverse loading from compression to tension in an AZ31 rolled $\mathrm{Mg}$ alloy sheet were investigated experimentally and using crystal plasticity finite-element simulations. Herein, the effect of twinning and detwinning activities on stress and strain behaviors, including yield stress, 
work-hardening, evolution of the Lankford value, and thickness strain, are discussed in detail. Electron backscatter diffraction (EBSD) was utilized to observe the microstructures, focusing on twinning and detwinning activities upon reverse loading.

\section{Experimental methods}

\subsection{Materials}

A commercially rolled AZ31 Mg alloy sheet with a thickness of $1.0 \mathrm{~mm}$ (Osaka Fuji) was used in this study. Specimens with length and width of the gauge section of 53.5 and $23 \mathrm{~mm}$, respectively [2], were prepared along the rolling direction and annealed at $350{ }^{\circ} \mathrm{C}$ for $1.5 \mathrm{~h}$. Fig. 1 shows the pole figures of the initial material. The conditions of the EBSD measurement are outlined below.

\subsection{Experimental procedures}

In this study, two reverse loading tests were performed. In the first test, reverse loading from in-plane compression to tension was continuously performed. The experimental procedure followed that described in detail in previous studies $[2,15]$. A small compressive force was applied through the thickness of a specimen during the test using comb-shaped dies [41] to suppress buckling during the compression. The through-thickness stress due to the compressive force was approximately $3 \%$ of the yield stress of the sample. The compressive force was maintained using a hydraulic pump for the duration of the test. Mineral hydraulic oil was used as a lubricant between the dies and specimens. The purpose of this test was to examine the work-hardening behavior during reverse loading from compression to tension. A strain gauge (Kyowa electronic instruments, KFEM) was used to measure strains in the loading direction.

In the second test, after a specimen was subjected to compression to a prescribed strain, it was unloaded and removed from the experimental setup, including the comb-shaped dies. The specimen was then clamped and subjected to tension without using the comb-shaped dies. The purpose of this test was to measure the evolution of the Lankford value during tension in pre-compressed sheets. Thus, the sheet was unloaded at strain intervals of $1 \%$. It should be noted that the dimensions of the pre-compressed sheet at the beginning of the tension test were used as the initial configuration when strains were measured. A strain gauge was used to measure the axial strain, $\varepsilon_{l}$, while a micrometer was used to measure the width strain, $\varepsilon_{w}$, after unloading. The Lankford value, $r$, was calculated assuming a constant volume as follows:

$$
r=\frac{\varepsilon_{w}}{\varepsilon_{t}}=-\frac{\varepsilon_{w}}{\left(\varepsilon_{l}+\varepsilon_{w}\right)}
$$


where $\varepsilon_{t}$ is the thickness strain. Using the abovementioned procedure, the Lankford value could only be measured at unloaded points. The initial strain rate was set to 6.67 $\mathrm{x} 10^{-4} \mathrm{~s}^{-1}$. It should be noted that the trends in the stress-strain curve of the pre-compressed sheets remained unchanged regardless of the use of comb-shaped dies.

For the EBSD measurement, the cross section normal to the rolling direction of the specimen was polished using a cross-section polisher prior to measurement. The step size was set to $0.45 \mu \mathrm{m}$. The OIM-Analysis 7.2.1 (TSL Solutions) software was used to analyze the inverse pole figure (IPF) maps and pole figures. It should be noted that the data were not taken into consideration if their confidence index was smaller than 0.1.

3. Crystal plasticity finite-element method

A crystal plasticity finite-element method program developed in-house by the authors was used in this study. The detailed formulation has been explained elsewhere [6, 14, 33-35], and a brief description is given here. To represent the plastic deformation of the $\mathrm{Mg}$ alloy sheet, basal $<\mathrm{a}>\mathrm{slip}$, prismatic $<\mathrm{a}>$ slip, pyramidal $<\mathrm{c}+\mathrm{a}>\operatorname{slip}$, and \{10-12\} twinning were taken into consideration. The following rate-dependent constitutive equation was used to describe the slip rate of the $\alpha$ slip system $\&^{\alpha}$ :

$$
\frac{\not \&}{\not \&}=\left|\frac{\tau^{\alpha}}{\tau_{\mathrm{Y}}^{\alpha}}\right|^{\frac{1}{m}} \operatorname{sign}\left(\tau^{\alpha}\right),
$$

where $\tau^{\alpha}$ is the resolved shear stress (RSS), $\not \&$ is the reference slip rate, $m$ is the rate-sensitivity coefficient, and $\tau_{\mathrm{Y}}^{\alpha}$ is the slip resistance, whose evolution is given by

$$
=\sum_{\beta} q_{\alpha \beta} h|\not \&|,
$$

where $q_{\alpha \beta}$ is the latent hardening matrix, and $h$ denotes the rate of hardening and is given as follows

$$
h=h_{0},
$$

and

$$
h=h_{0}\left(1-\frac{\tau_{0}}{\tau_{\infty}}\right) \exp \left(-\frac{h_{0} \bar{\gamma}}{\tau_{\infty}}\right) \text { with } \bar{\gamma}=\sum_{\alpha} \int||^{\&} \mid \mathrm{d} t,
$$

where $h_{0}$ and $\tau_{\infty}$ are the hardening parameters, and $\tau_{0}$ is the CRSS. Following previous studies [6, 14, 33-35], Eq. (4) was used for basal<a> slip, whereas Eq. (5) was 
used for non-basal slip calculations.

A twinning and detwinning model previously proposed by the authors was utilized. As in the case of slip activity, Eqs. (2), (3), and (4) were used to model the shear strain rate induced by twinning, $\mathcal{\gamma}_{\mathrm{win}}^{\alpha}$. The volume fraction of twinning, $f^{\alpha}$, was used for the twinning rotation criterion and was calculated in the form

$$
f^{\alpha}=\frac{\gamma_{\text {twin }}^{\alpha}}{\gamma_{\text {ref }}}, \quad \gamma_{\text {twin }}^{\alpha}=\int\left|\gamma_{\text {twi }}^{\alpha}\right| d t
$$

where $\gamma_{\text {ref }}$ is the reference shear strain due to twinning. For the detail formulation, refer to cited literature [6, 14, 33-35].

The aforementioned crystal plasticity model was incorporated as constitutive equations into the static finite-element method and explicit time integration was employed. The representative volume element was a cube with 10 divisions in each direction, and 8-node solid elements with selective reduced integration were used. The length of each side of the volume element was $10 \mathrm{~mm}$. The $x, y$, and $z$ directions were identified to be the rolling, transverse, and normal directions, respectively. Plane symmetric boundary conditions were assigned to the planes $x=0, y=0$, and $z=0$, whereas traction-free boundary conditions were assigned to planes $y=10$ and $z=10$. Small displacement increments were assigned to the nodes on the plane $x=10$ to simulate monotonic and reverse loadings. The Green-Lagrange strain tensor was used to evaluate deformation. To evaluate the Lankford value in the pre-compressed sheets, the geometry of the representative volume element was initialized after the model was compressed and unloaded, mirroring the experimental conditions. Thus, the strains that occurred only during subsequent tension could be evaluated and more easily compared to the experimental results.

The initial crystal orientation assigned to the 8 integration points in an element was identical. In this study, 1000 initial orientations were taken into consideration. The initial orientations were chosen in a random order from the results of the EBSD measurement. It should be noted that previous studies [33] have shown that this number of initial orientations was sufficient to investigate the macroscopic and mesoscopic deformation behavior of $\mathrm{Mg}$ alloy sheets.

The material constants, hardening parameters, and latent hardening parameters used for the calculations are listed in Tables 1, 2, and 3, respectively. Following the parameter identification procedure described in detail in a previous report [6], the parameters were determined to reproduce the evolution of the Lankford value under tension and the stress-strain curves under monotonic tension, monotonic compression, and $4 \%$ compression followed by tension (Fig. 2). 


\section{Experimental and simulation results}

In the following section, the stress and strain behaviors after stress reversal, i.e., during subsequent tension, are explained by experimental and simulation results.

\subsection{Work-hardening behavior}

Fig. 3 shows the stress-strain curves under reverse loading from compression to tension using various compressive strains, and Fig. 4 depicts the evolution of the work-hardening rate during subsequent tension. The well-known sigmoidal curves occur irrespective of compressive strain, i.e., after yielding, a plateau region occurs followed by a rapid increase in stress. The deformation until the peak gradient, $g_{\mathrm{T}}$, which is indicated by a star mark in Fig. 4 , is classified as the first stage, whereas the subsequent deformation is termed the second stage. However, the sigmoidal trend depends on the compressive strain, as reported previously [15]. Specifically, the plateau region tends to increase with compressive strain. On the other hand, the peak gradient, $g_{\mathrm{T}}$, tends to decrease with increasing compressive strain. The simulation results predict these hardening behaviors fairly accurately, although the stress level in the second stage is underestimated for the $6 \%, 8 \%$, and $10 \%$ cases.

To examine the abovementioned behaviors more quantitatively, the peak gradient, $g_{\mathrm{T}}$, and the amount of strain in the first stage, $\varepsilon_{\mathrm{T}}$, were evaluated (Fig. 4). The variations in $g_{\mathrm{T}}$ and $\varepsilon_{\mathrm{T}}$ as a function of the absolute compressive strain are shown in Fig. 5. $\varepsilon_{\mathrm{T}}$ increases with the absolute compressive strain. Interestingly, the magnitude of $\varepsilon_{\mathrm{T}}$ determined experimentally is very close to that of the absolute compressive strain. In contrast, $g_{\mathrm{T}}$ decreases with increasing absolute compressive strain. The simulation results of $g_{\mathrm{T}}$ agree well with the experimental results. On the contrary, the simulation of $\varepsilon_{\mathrm{T}}$ agrees well with the experimentally determined values for the $2 \%, 4 \%$, and $6 \%$ cases, while it underestimated the experimental results for the $8 \%$ and $10 \%$ cases.

\subsection{Yield stress}

As observed in the stress-strain curves under reverse loading, the yield stress in the subsequent tension is smaller than that of the monotonic tension. Previous studies [18, $19,21,23]$ reported that the yield stress in the subsequent tension increased when the sheet was annealed after compression. Thus, the pre-compressed sheets were annealed at $160{ }^{\circ} \mathrm{C}$ for $12 \mathrm{~h}$ before being subjected to tension. This annealing condition was used to remove residual stresses and to reduce the dislocation density while maintain the 
microstructures, including twinned regions [42]. In the simulation, residual stresses were removed and $\tau_{\mathrm{Y}}^{\alpha} \mathrm{s}$ in Eq. (2) were initialized after the sheet was macroscopically unloaded from compression to imitate the annealing process, focusing on the effects of residual stresses and work-hardening.

Fig. 6 shows the stress-strain curves of the annealed sheets. Compared to the results of the non-annealed sheet (Fig. 3), the yield stress increases, and a clear plateau region appears after annealing, consistent with previous studies. In contrast, the work-hardening behavior in the second stage was unaffected by the annealing process. Fig. 7 shows the relationship between the $0.2 \%$ proof stress and absolute compressive strain. The $0.2 \%$ proof stress is much larger in the annealed sheet than that in the non-annealed sheet, and the extent of the increase is nearly irrespective of compressive strain. These results suggest that the annealing significantly affects the $0.2 \%$ proof stress, while its effect on the subsequent deformation in the second stage is negligible. The simulation results are in qualitatively good agreement with those determined experimentally despite the smaller increase in the $0.2 \%$ proof stress compared with the experiment. It should be noted that the simulation results remained unchanged whether or not the $\tau_{\mathrm{Y}}^{\alpha}$ s were initialized, suggesting that the increase in the $0.2 \%$ proof stress achieved in the simulation is primarily due to the removal of residual stresses.

\subsection{Evolution of the strain and Lankford value}

Fig. 8 shows the evolution of the absolute thickness strain during tension for the $4 \%$ case. The sheet was unloaded in strain intervals of $1 \%$, and the thickness strain was evaluated after unloading. The thickness strain increases linearly as a function of tensile strain until a strain of approximately $3 \%$, and then the rate of increase becomes slightly smaller. Interestingly, the rate of increase changes at the onset of the second stage, indicating that the thickness evolution is different between the first and second stages. A similar thickness strain evolution occurs irrespective of compressive strain, although the results are not shown here. A similar evolution was observed in the simulation, although the rate of increase in the second stage was underestimated.

Fig. 9 shows the Lankford value evolution for various compressive strains. The Lankford value is relatively small and further decreases during the first stage. This may be because of the generation of the large thickness strain. Thereafter, the Lankford value increases during the second stage due to the decrease in the rate of increase of the thickness strain. Because the onset of the second stage is delayed with the increase in 
the compressive strain, the Lankford value decreases with increasing compressive strain, consistent with previous reports [6]. The simulation results also indicate a similar evolution, although in the simulation results the Lankford values were underestimated in the first stage and increase to a larger extent in the second stage than those experimentally determined, irrespective of the compressive strain. These discrepancies are likely due to the increasing rate of thickness strain being larger in the first stage and smaller in the second stage in the simulation compared to the experimental results (Fig. 8).

\section{Discussion}

In this section, the results described previously are discussed with respect to the simulation results.

\subsection{Work-hardening behavior}

In a previous study [15], the difference in sigmoidal trends depended on the compressive strain, and was assumed to be due to the difference in twinning and detwinning activities. Simulation results were used to support this hypothesis and to discuss the underlying mechanism in detail. The mesoscopic deformation behavior was evaluated using relative activity of family, $i$, which can be defined as

$$
r_{i}=\frac{\sum_{n_{s}}^{n} \sum_{\alpha}^{k}\left|\&^{\left.n_{s}, \alpha\right)}\right|}{\sum_{n_{s}}^{n} \sum_{\beta}^{N}|| \&^{\left.n_{s}, \beta\right)} \mid},
$$

where $k$ is the number of systems of family $i, n$ is the number of grains, and $N$ is the number of all slip and twinning systems.

The results obtained with compressive strains of $4 \%$ and $8 \%$ were used as representative examples. Fig. 10 shows the evolution of relative activities and the evolution of the $4 \%$ case (Fig. 10 (a)) can be explained as follows. The basal slip and twinning activities are dominant during compression, whereas after reverse loading the detwinning activity is pronounced until reaching an accumulated strain of approximately $7 \%$. Thereafter, the detwinning activity decreases rapidly to zero, whereas the activity of the prismatic slip begins to increase. Clearly, the shift from detwinning-dominant to slip-dominant deformation is sharp. The second stage begins at an accumulated strain of approximately $8 \%$, as indicated by the star mark, suggesting that the sharp shift in deformation mode results in an equally sharp sigmoidal curve. The aforementioned twinning and detwinning behaviors are consistent with the results of the IPF maps shown in Fig. 11. Namely, twinned regions are pronounced at an 
accumulated strain of $4 \%$, but become smaller as the tensile deformation progresses. Eventually, the twinned regions become negligible at strains of $7 \%$ and $10 \%$.

The strain evolution for the $8 \%$ case (Fig. 10 (b)) is significantly different from that of the $4 \%$ case. During compression, the twinning activity begins to decrease gradually at an accumulated strain of approximately $3 \%$. Thus, in the latter stage of compression, basal slip and twinning in addition to prismatic slip and pyramidal $<c+a>$ slip are active. After reversing the loading direction, detwinning activity is pronounced in the initial stage, similar to the $4 \%$ case (Fig. 10 (a)) and remains stable until an accumulated strain of approximately $11 \%$, when it subsequently decreases. However, the decreasing rate is more gradual and much larger strain is necessary for detwinning activity to reach zero compared to the $4 \%$ case. Therefore it can be concluded that twinning and prismatic slip are already active before the detwinning activity reaches zero. Clearly, the shift from the detwinning-dominant to slip-dominant deformation is more gradual in the $8 \%$ case than that in the $4 \%$ case. Detwinning evolution is consistent with the microstructure evolution shown in Fig. 12. Many twinned regions remain at an accumulated strain of $13 \%$ and the crystal orientations remain dispersed. Moreover, twinned regions remain at an accumulated strain of $15 \%$. This suggests that the sigmoidal curve becomes less pronounced with increasing compressive strain because the deformation mode shift becomes more gradual, supporting the hypothesis of the previous study [15].

It should be noted that the simulation results tended to overestimate the twin fraction for the $4 \%$ and $8 \%$ cases, as shown in Fig. 13, although the evolution is qualitatively in good agreement with the experimental results for both cases. Moreover, the $\varepsilon_{\mathrm{T}}$ is smaller in the simulation than in the experiment under large compressive strains (Fig. 5). These results suggest that the twinning and detwinning model can be further improved, and will be the focus of our future work.

\subsection{Yield stress}

The increase in the $0.2 \%$ proof stress by annealing can be attributed to several factors. Recently, Cui et al. [23] qualitatively discussed the effects of back stress, which is generated near twin boundaries, and friction stress, which is affected by various factors such as solute concentration, precipitates, and ordered segregation of solute atoms in twin boundaries [43,44]. Because residual stresses notably affect the $0.2 \%$ proof stress in the subsequent tension, as observed in the simulation results (Figs. 6 and 7 ), their effect on the $0.2 \%$ proof stress can be examined in detail using crystal plasticity analysis. 
To investigate the effect of removing residual stresses on mesoscopic deformation, Fig. 14 shows the evolution of the relative activities during the subsequent tension for the $4 \%$ case. Fig. 14 (b) compares the initial relative activities, designated by the broken line in Fig. 14 (a), between the non-annealed and annealed sheets. It should be noted that in Fig. 14 (b) only the results of the basal slip and detwinning are shown because the activities of other slip systems are initially negligible for both cases. Compared to the non-annealed sheet (Fig. 10 (a)), the overall evolution is nearly independent of the annealing process, while the detwinning activity differs (Fig. 14 (b)). The detwinning activity increases from the beginning in the non-annealed sheet, while in the annealed sheet detwinning is not active until a strain of approximately 0.0015 , where its activity increases rapidly. This difference in the detwinning activity is consistent with previous experimental observations [21,23]. In contrast, subsequent activities are nearly independent of annealing. Although the detailed results are not given here to avoid redundancy, the microstructure observation of the annealed sheet showed that the evolution of detwinning at high strains was also nearly independent of annealing, consistent with the simulation. Clearly, initial detwinning activity of subsequent tension is significantly affected by residual stresses, suggesting they play a significant role as back stresses to detwinning.

To quantitatively discuss how the residual stresses affect detwinning activity, Fig. 15 shows the histograms of RSS for active twinning systems in the $4 \%$ case. Before unloading, the RSSes are $\geq 40 \mathrm{MPa}$ in most of the active twinning systems (Fig. 15 (a)) due to the fact that the initial CRSS of twinning was set to $40 \mathrm{MPa}$. After the sheet was macroscopically unloaded, nearly $30 \%$ of the active twinning systems possess negative RSSes (Fig. 15 (b)), because of mesoscopically non-uniform deformation. These negative RSSes after unloading likely act as back stresses to detwinning during the subsequent tension, which is consistent with the experimental results obtained using in-situ neutron diffraction measurements [18]. Moreover, similar back stresses also appear for the basal slip systems, as previously discussed in the literature [33]. It is likely that these back stresses eventually result in early yielding in the subsequent tension.

As previously mentioned, the increase in the $0.2 \%$ proof stress obtained by simulation is smaller than that of the experimentally determined values. This discrepancy is likely due to only considering the effect of mechanical residual stresses, while other factors such as precipitation and segregation of solute atoms [23] were not considered.

\subsection{Evolution of the strain and Lankford value}


Because of the strong basal texture of the $\mathrm{Mg}$ alloy sheet, it is reasonable to assume that detwinning primarily affects the thickness strain. Therefore, the effect of detwinning activity on the strain evolution during reverse loading is discussed in relation to the simulation results. To examine the correlation between detwinning activity and thickness strain evolution quantitatively, the evolution of the $\mathrm{zz}$ components (normal components in the thickness direction) of the plastic part of the velocity gradient tensor $L, L_{\mathrm{zz}}^{\mathrm{p}}$, were evaluated. They were given in the form

$$
L_{z z}^{\mathrm{p}}=\boldsymbol{L}^{\mathrm{p}}:\left(\boldsymbol{e}_{\mathrm{z}} \otimes \boldsymbol{e}_{\mathrm{z}}\right), \quad \boldsymbol{L}^{\mathrm{p}}=\sum_{\alpha=1}^{N} \& \&\left(\boldsymbol{s}^{\alpha} \otimes \boldsymbol{m}^{\alpha}\right),
$$

where $\boldsymbol{s}^{\alpha}$ and $\boldsymbol{m}^{\alpha}$ denote the unit vectors representing the slip direction and slip plane normal of the $\alpha$ slip/twinning system, respectively, and $N$ denotes the number of slip and twinning systems. $L_{\text {zz }}^{\mathrm{p}}$ was further decomposed into components contributed by the slip $L_{\mathrm{zz}}^{\mathrm{p} \text { slip }}$ and twinning $L_{\mathrm{zz}}^{\mathrm{p} \text { twin }}$ as follows

$$
\begin{gathered}
L_{\mathrm{zz}}^{\mathrm{p}}=L_{\mathrm{zz}}^{\mathrm{p} \text { slip }}+L_{\mathrm{zz}}^{\mathrm{p} \text { twin }} \\
L_{\mathrm{zz}}^{\mathrm{p} \text { slip }}=\left[\sum_{\alpha=1}^{N_{\text {slip }}} \& \&\left(\boldsymbol{s}^{\alpha} \otimes \boldsymbol{m}^{\alpha}\right)\right]:\left(\boldsymbol{e}_{\mathrm{z}} \otimes \boldsymbol{e}_{\mathrm{z}}\right), \quad L_{\mathrm{zz}}^{\mathrm{p} \text { twin }}=\left[\sum_{\alpha=1}^{N_{\text {twin }}} \& \&\left(\boldsymbol{s}^{\alpha} \otimes \boldsymbol{m}^{\alpha}\right)\right]:\left(\boldsymbol{e}_{\mathrm{z}} \otimes \boldsymbol{e}_{\mathrm{z}}\right),
\end{gathered}
$$

where $N_{\text {slip }}$ and $N_{\text {twin }}$ denote the numbers of slip and twinning systems, respectively; thus, $N=N_{\text {slip }}+N_{\text {twin }}$ is true. Note that the averages of all integration points were used to evaluate $L_{\mathrm{zz}}^{\mathrm{p}}$.

Fig. 16 (a) shows the evolution of the $L_{\mathrm{zz}}^{\mathrm{p} \text { slip }}$ and $L_{\mathrm{zz}}^{\mathrm{p} \text { twin }}$ values during the subsequent tension for the $4 \%$ case. The evolution of the absolute thickness strain is also shown. In the first stage, both slip and twinning activities contribute to the thickness strain, and the magnitude of $L_{\mathrm{zz}}^{\mathrm{p} \text { twin }}$ is larger than that of $L_{\mathrm{zz}}^{\mathrm{p} \text { slip }}$. In contrast, in the second stage, $L_{\mathrm{zz}}^{\mathrm{p} \text { slip }}$ is similar to that of the first stage, while $L_{\mathrm{zz}}^{\mathrm{p} \text { twin }}$ becomes almost negligible due to the detwinning activity reaching almost zero. These results suggest that thickness strain is contributed to by both slip and detwinning in the first stage, whereas only slip activity contributes in the second stage. Thus, the increasing rate of thickness strain is smaller in the second stage compared to that in the first stage. Moreover, these results indicate that, under these conditions, more than $50 \%$ of the thickness strain can be explained by detwinning activity in the first stage.

For the $8 \%$ case (Fig. $16(\mathrm{~b})$ ), the evolution of $L_{\mathrm{zz}}^{\mathrm{p} \text { slip }}$ and $L_{\mathrm{zz}}^{\mathrm{p} \text { twin }}$ in the first stage is similar to that of the $4 \%$ case, which results in the similar increasing rate of thickness strain between that of the $4 \%$ and $8 \%$ cases. In contrast, the evolution observed in the second stage is notably different from that of the $4 \%$ case. The magnitude of the $L_{\mathrm{zz}}^{\mathrm{p} \text { slip }}$ value is much larger than that of the first stage and the $4 \%$ case. This large $L_{\mathrm{zz}}^{\mathrm{p} \text { slp }}$ 
presumably occurs because many twinned regions remain in the second stage and the crystal orientations remain dispersed (Figs. 12 and 13). Therefore, various slip activities can contribute to the thickness strain. In addition, $L_{\mathrm{zz}}^{\mathrm{p} \text { twin }}$ is much smaller than $L_{\mathrm{zz}}^{\mathrm{p} \text { slip }}$ and becomes positive because the twinning activity is larger than the detwinning activity in the second stage (Fig. 10 (b)). The abovementioned results show that the larger $L_{\mathrm{zz}}^{\mathrm{p} \text { slip }}$ value in the second stage yields larger thickness strain for the $8 \%$ case. Thus, the increasing rate of thickness strain in the second stage is larger for the $8 \%$ case than for the $4 \%$ case, and a smaller Lankford value is obtained for the $8 \%$ case.

\section{Conclusions}

In this study, a compression-tension test was performed using a rolled AZ31 magnesium alloy sheet to study the effects of twinning and detwinning on the stress and strain behaviors. A crystal plasticity finite-element method was used to discuss the deformation mechanism. The conclusions of this study can be summarized as follows.

(1) During subsequent tension, the yield stress is quite small and a sigmoidal curve is observed. These stress behaviors are independent of compressive strain, while the sigmoidal curve becomes less pronounced as the compressive strain increases. The yield stress increases when the sheet is annealed prior to reverse loading, irrespective of compressive strain. The Lankford value during subsequent tension is relatively small and further decreases in the first work-hardening stage, while it increases in the second stage. The Lankford value decreases with increasing compressive strain. It was also shown that the crystal plasticity analysis predicts the abovementioned stress and strain behaviors fairly accurately.

(2) The simulation results show that the shift from detwinning-dominated to slip-dominated deformation becomes more gradual as the compressive strain increases. Thus, the sigmoidal curve becomes less pronounced with increasing compressive strain.

(3) The simulation results show that, in the case of $4 \%$ compression followed by tension, approximately $30 \%$ of the active twinning systems have negative resolved shear stresses after macroscopic unloading of the sheet. It is likely that these negative stresses support the detwinning activity during subsequent tension as back stresses, which results in small yield stress in subsequent tension, and thus, the yield stress increases when the sheet is annealed before reverse loading. 
(4) By analyzing the plastic part of the velocity gradient tensor, it is suggested that in the case of $4 \%$ compression followed by tension the thickness strain is composed of both slip and detwinning activities in the first work-hardening stage. Conversely, only slip activity contributes toward the thickness strain in the second stage. Thus, the thickness strain increases to a larger extent in the first stage compared to the second stage. This difference in the thickness strain evolution results in a large difference in the Lankford values between the first and second stages. Under these conditions, more than $50 \%$ of thickness strain can be explained by detwinning in the first stage.

It should be noted that the texture change during the deformation would also affect the stress and strain behaviors. For instance, the effects of slip and twinning activities in the twinned regions on the stress and strain behaviors were examined by using crystal plasticity simulations in our previous study [6]. The simulation results showed that their effects on the stress and strain behaviors after stress reversal were not negligible, especially in the stress-strain response. Detailed investigation on the effect of texture change will be conducted in our future work.

\section{Acknowledgements}

The authors wish to acknowledge the help of Mr. Sohei Uchida of the Osaka Research Institute of Industrial Science and Technology in conducting the EBSD measurements. This study was partially supported by JSPS KAKENHI Grant number 17H03428, 17K06858, and the Photon and Quantum Basic Research Coordinated Development Program from the Ministry of Education, Culture, Sports, Science and Technology, Japan.

Data availability

The raw and processed data required to reproduce these findings cannot be shared at this time due to technical and time limitations.

\section{References}

[1] Lou, X.Y., Li, M., Boger, R.K., Agnew, S.R., Wagoner, R.H., Hardening evolution of AZ31B Mg sheet, International Journal of Plasticity, 23(2007), 44-86.

[2] Hama, T., Kariyazaki, Y., Hosokawa, N., Fujimoto, H., Takuda, H., Work-hardening behaviors of magnesium alloy sheet during in-plane cyclic loading, Materials Science and Engineering A, 551(2012), 209-217.

[3] Kurukuri, S., Worswick, M.J., Tari, D.G., Mishra, R.K., Rate sensitivity and 
tension-compression asymmetry in AZ31B magnesium alloy sheet, Philosophical Transactions A Royal Society Publishing, 372(2014), 20130216.

[4] Park, S.H., Hong, S.-G., Lee, C.S., In-plane anisotropic deformation behavior of rolled Mg-3Al-1Zn alloy by initial $\{10-12\}$ twins, Materials Science and Engineering A, 570(2013), 149-163.

[5] Sarker, D., Chen, D.L., Dependence of compressive deformation on pre-strain and loading direction in an extruded magnesium alloy: texture, twinning and de-twinning, Materials Science and Engineering A, 596(2014), 134-144.

[6] Hama, T., Tanaka, Y., Uratani, M., and Takuda, H., Deformation behavior upon two-step loading in a magnesium alloy sheet, International Journal of Plasticity, 82(2016), 283-304.

[7] Huang, X., Suzuki, K., Chino, Y., and Mabuchi, M., Influence of initial texture on cold deep drawability of $\mathrm{Mg}-3 \mathrm{Al}-1 \mathrm{Zn}$ alloy sheets, Materials Science and Engineering A, 565(2013), 359-372.

[8] Hama, T., Kariyazaki, Y., Ochi, K., Fujimoto, H., and Takuda, H., Springback characteristics of Magnesium alloy AZ31B in draw-bending, Materials Transactions, 51-4 (2010), 685-693.

[9] Frankel, G.S., Magnesium alloys ready for the road, Nature Materials, 14(2015), 1189-1190.

[10] Guo, T., Siska, F., Barnett, M.R., Distinguishing between slip and twinning events during nanoindentation of magnesium alloy AZ31, Scripta Materialia, 110(2016), 10-13. [11] Wu, L., Agnew, S.R., Ren, Y., Brown, D.W., Clausen, B., Stoica, G.M., Wenk, H.R., and Liaw, P.K., The effects of texture and extension twinning on the low-cycle fatigue behavior of a rolled magnesium alloy, AZ31B, Materials Science and Engineering A, 527(2010), 7057-7067.

[12] Proust, G., Tom_e, C.N., Jain, A., Agnew, S.R., Modeling the effect of twinning and detwinning during strain-path changes of magnesium alloy AZ31, International Journal of Plasticity, 25(2009), 861-880.

[13] Wang, H., Wu, P.D., Wang, J., Tome, C.N., A crystal plasticity model for hexagonal close packed (HCP) crystals including twinning and de-twinning mechanisms, International Journal of Plasticity, 49(2013), 36-52.

[14] Hama, T., Mayama, T., Takuda, H., Deformation behavior of a Magnesium alloy sheet with random crystallographic orientations under various loading paths, The Romanian Journal of Technical Sciences-Applied Mechanics, 60(2015), 16.

[15] Hama, T., Nagao, H., Kuchinomachi, Y., Takuda, H., Effect of pre-strain on work-hardening behavior of magnesium alloy sheets upon cyclic loading, Materials 
Science and Engineering A, 591(2014), 69-77.

[16] Hama, T., and Takuda, H., Work-hardening behavior upon reverse loading in a rolled AZ31 magnesium alloy sheet, Key Engineering Materials, 622-623 (2014), 603-608.

[17] Partridge, P.G., Cyclic twinning in fatigued close-packed hexagonal metals. Philosophical Magazine, 12(1965), 1043-1054.

[18] Wu, L., Agnew, S.R., Brown, D.W., Stoica, G.M., Clausen, B., Jain, A., Fielden, D.E., and Liaw, P.K., Internal stress relaxation and load redistribution during the twinnin-detwinning-dominated cyclic deformation of a wrought magnesium alloy, ZK60A, Acta Materialia, 56(2008), 3699-3707.

[19] Park, S.H., Lee, J.H., Huh, Y.-H., and Hong, S.-G., Enhancing the effect of texture control using $\{10-12\}$ twins by retarding detwinning activity in rolled $\mathrm{Mg}-3 \mathrm{Al}-1 \mathrm{Zn}$ alloy, Scripta Materialia, 69(2013), 797-800.

[20] Hagihara, K. and Nakano, T., Experimental clarification of the cyclic deformation mechanisms of $\beta$-type $\mathrm{Ti}-\mathrm{Nb}$-Ta-Zr-alloy single crystals developed for the single-crystalline implant, International Journal of Plasticity, 98(2017), 27-44.

[21] Xin, Y., Zhang, Y., Yu, H., Chen, H., and Liu, Q., The influence of a secondary twin on the detwinning deformation of a primary twin in $\mathrm{Mg}-3 \mathrm{Al}-1 \mathrm{Zn}$ alloy, Materials Science and Engineering A, 606(2014), 81-91.

[22] Xin, Y., Zhou, X., Lv, L., and Liu, Q., The different effects of solute segregation at twin boundaries on mechanical behaviors of twinning and detwinning, Materials Science and Engineering A, 644(2015), 365-373.

[23] Cui, Y., Li, Y., Wang, Z., Lei, Q., Koizumi, Y., and Chiba, A., Regulating twin boundary mobility by annealing in magnesium and its alloys, International Journal of Plasticity, 99(2017), 1-18.

[24] Brown, D.W., Agnew, S.R., Bourke, M.A.M., Holden, T.M., Vogel, S.C., and Tomé, C.N., Internal strain and texture evolution during deformation twinning in magnesium, Materials Science and Engineering A, 399(2005), 1-12.

[25]Chen, P., Li, B., Culbertson, D., and Jiang, Y., Contribution of extension twinning to plastic strain at low stress stage deformation of a Mg-3Al-1Zn alloy, Materials Science and Engineering A, 709(2018), 40-45.

[26] Steglich, D., Tian, X., Bohlen, J., Kuwabara, T., Mechanical testing of thing sheet magnesium alloys in biaxial tension and uniaxial compression, Experimental Mechanics, 54(2014), 1247-1258.

[27] Culbertson, D., Yu, Q., Wang, J., and Jiang, Y., Pre-compression effect on microstructure evolution of extruded pure polycrystalline magnesium during reversed 
tension load, Materials Characterization, 134(2017), 41-48.

[28]Wang, H., Lee, S.Y., Gharghouri, M.A., Wu, P.D., and Yoon, S.G., Deformation behavior of $\mathrm{Mg}-8.5 \mathrm{wt} . \% \mathrm{Al}$ alloy under reverse loading investigated by in-situ neutron diffraction and elastic viscoplastic self-consistent modeling, Acta Materialia, 107(2016), 404-414.

[29] Mokdad, F., Chen, D.L., and Li, D.Y., Twin-Twin interactions and contraction twin formation in an extruded magnesium alloy subjected to an alteration of compressive direction, Journal of Alloys and Compounds, 737(2018), 549-560.

[30] Agnew, S.R., Singh, A., Calhoun, C.A., Mulay, R.P., Bhattacharyya, J.J., Somekawa, H., Mukai, T., Clausen, B., and Wu, P.D., In-situ neutron diffraction of a quasicrystal-containing $\mathrm{Mg}$ alloy interpreted using a new polycrystal plasticity model of hardening due to $\{10.2\}$ tensile twinning, International Journal of Plasticity, 100(2018), $34-51$.

[31] Wu, B.L., Duan, G.S., Du, X.H., Song, L.H., Zhang, Y.D., Philippe, M.J., and Esling, C., In situ investigation of extension twinning-detwinning and its effect on the mechanical behavior of AZ31B magnesium alloy, Materials and Design, 132(2017), 57-65.

[32] Dong, S., Yu, Q., Jian, Y., Dong, J., Wang, F., Li, J., and Ding, W., Characteristic cyclic plastic deformation in ZK60 magnesium, International Journal of Plasticity, 91(2017), 25-47.

[33] Hama, T., Takuda, H., Crystal-plasticity finite-element analysis of inelastic behavior during unloading in a magnesium alloy sheet. International Journal of Plasticity, 27(2011), 1072-1092.

[34] Hama, T., Takuda, H., Crystal plasticity finite-element simulation of work-hardening behavior in a magnesium alloy sheet under biaxial tension, Computational Materials Science, 51(2012), 156-164.

[35] Hama, T., Takuda, H., Crystal plasticity finite-element simulation of deformation behavior in a magnesium alloy sheet considering detwinning, Steel Research International, Special Edition, (2012), 1115-1118.

[36] Abdolvand, H., Majkut, M., Oddershede, J., Schmidt, S., Lienert, U., Diak, B.J., Withers, P.J., Daymond, M.R., On the deformation twinning of Mg AZ31B: a threedimensional synchrotron X-ray diffraction experiment and crystal plasticity finite element model, International Journal of Plasticity, 70(2015), 77-97.

[37] Dogan, E., Vaughan, M.W., Wang, S.J., Karamana, I., Proust, G., Role of starting texture and deformation modes on low-temperature shear formability and shear localization of Mg-3Al-1Zn alloy, Acta Materialia, 89(2015), 408-422. 
[38] Kabirian, F., Khan, A.S., Gnaupel-Herlod, T., Visco-plastic modeling of mechanical responses and texture evolution in extruded AZ31 magnesium alloy for various loading conditions, International Journal of Plasticity, 68(2015), 1-20.

[39] Sanchez-Martín, R., Perez-Prado, M.T., Segurado, J., Molina-Aldareguia, J.M., Effect of indentation size on the nucleation and propagation of tensile twinning in pure magnesium, Acta Materialia, 93(2015), 114-128.

[40] Wang, H., Raeisinia, B., Wu, P.D., Agnew, S.R., and Tomé, C.N., Evaluation of self-consistent polycrystal plasticity models for magnesium alloy AZ31B sheet, International Journal of Solids and Structures, 47(2010), 2905-2917.

[41] Kuwabara, T., Advances in experiments on metal sheets and tubes in support of constitutive modeling and forming simulations, International Journal of Plasticity, 23(2007), 385-419.

[42] Xin, Y., Zhou, X., Chen, H., Nie, J.-F., and Zhang, H., Annealing hardening in detwinning deformation of $\mathrm{Mg}-3 \mathrm{Al}-1 \mathrm{Zn}$ alloy, Materials Science and Engineering A, 594(2014), 287-291.

[43] Robson, J.D., Stanford, N., and Barnett, M.R., Effect of precipitate shape on slip and twinning in magnesium alloys, Acta Materialia, 59(2011), 1945-1956.

[44] Nie, J.F., Zhu, Y.M., Liu, J.Z., and Fang, X.Y., Periodic segregation of solute atoms in fully coherent twin boundaries, Science, 340(2013), 957-960.

Figure captions

Fig. 1 Initial pole figures of the material used in experiment.

Fig. 2 Experimental and simulation results of (a) the stress-strain curves under tension, compression, and reverse loading, and (b) evolution of the Lankford value.

Fig. 3 Stress-strain curves under reverse loading with different compressive strains. Results are shown for the compressive strains of (a) $2 \%, 4 \%$, and $6 \%$, and (b) $8 \%$ and $10 \%$.

Fig. 4 Evolution of the work-hardening rate during subsequent tension. Results are shown for the compressive strains of (a) $2 \%, 4 \%$, and $6 \%$, and (b) $8 \%$ and $10 \%$. The $\varepsilon_{\mathrm{T}}$ and $g_{\mathrm{T}}$ values are defined as the point where the peak gradient occurs, and denoted by the star mark.

Fig. 5 Variations of $g_{\mathrm{T}}$ and $\varepsilon_{\mathrm{T}}$ as functions of absolute compressive strain measured in Fig. 4. Circles and triangles denote $g_{\mathrm{T}}$ and $\varepsilon_{\mathrm{T}}$, respectively. Solid and open marks denote the simulation and experimental results, respectively.

Fig. 6 Stress-strain curves after stress reversal obtained using non-annealed and annealed sheets. The compressive strains are (a) $2 \%$ and $4 \%$, and (b) $6 \%$ and $8 \%$. Solid 
and broken lines denote simulation and experimental results, respectively.

Fig. 7 Relationship between the $0.2 \%$ proof stress during subsequent tension and absolute compressive strain.

Fig. 8 Evolution of the absolute thickness strain during tension. The compressive strain was $4 \%$. Solid and broken lines denote the simulation and experimental results, respectively.

Fig. 9 Evolution of the Lankford value during subsequent tension. Results are shown for the compressive strains of (a) $2 \%$ and $4 \%$ and (c) $6 \%$ and $8 \%$.

Fig. 10 Evolution of the relative activities during reverse loading with compressive strains of (a) $4 \%$ and (b) $8 \%$. The peak gradient occurs at strains denoted by star marks.

Fig. 11 IPF maps of (a) initial sheet and pre-compressed sheets with compressive strain of $4 \%$ measured at accumulated strains of approximately (b) 4\%, (c) $5 \%$, (d) 7\%, and (e) $10 \%$. The result of initial sheet corresponds to the pole figure shown in Fig. 1.

Fig. 12 IPF maps measured on a pre-compressed sheet with compressive strain of $8 \%$. Results are measured at accumulated strains of approximately (a) 10\%, (b) $11 \%$, (c) $13 \%$, and (d) $15 \%$.

Fig. 13 Evolution of the twin fraction. Solid lines and symbols denote the simulation and experimental results, respectively.

Fig. 14 Evolution of relative activities during subsequent tension for the annealed sheet with compressive strain of $4 \%$. Strain ranges are (a) from $0 \%$ to $10 \%$ and (b) from $0 \%$ to $1 \%$. In (b), only the results of basal and detwinning are shown, and results of the non-annealed sheet are also shown.

Fig. 15 Histograms of the resolved shear stress of active twinning systems. Results were measured at a compressive strain of $4 \%$ (a) before unloading and (b) after unloading.

Fig. 16 Evolution of $L_{z z}^{\mathrm{p} \text { twin }}$ and $L_{\mathrm{zz}}^{\mathrm{p} \text { slip }}$ for compressive strains of (a) $4 \%$ and (b) $8 \%$. Circles and triangles denote $L_{\mathrm{zz}}^{\mathrm{p} \text { twin }}$ and $L_{\mathrm{zz}}^{\mathrm{p} \text { slip }}$, respectively, and the broken line is the absolute thickness strain.

Table 1 Material constants used in the simulation

Table 2 Hardening parameters used in the simulation

Table 3 Latent hardening parameters used in the simulation 
Table 1 Material constants used in the simulation

\begin{tabular}{|c|c|c|c|c|}
\hline$E / G P a$ & $v$ & $m$ & $\not \&_{*} / s^{-1}$ & $\gamma_{\text {ref }}$ \\
\hline 42 & 0.3 & 0.02 & 0.001 & 0.17 \\
\hline
\end{tabular}


Table 2 Hardening parameters used in the simulation

\begin{tabular}{ccccccc}
\hline & & Basal & Prismatic & Pyramidal $<\mathrm{c}+\mathrm{a}>$ & Twinning & Detwinning \\
\hline$\tau_{0}$ & $/ \mathrm{MPa}$ & 25 & 95 & 100 & 40 & 35 \\
\hline$\tau_{\infty}$ & $/ \mathrm{MPa}$ & - & 230 & 190 & - & - \\
\hline$h_{0}$ & $/ \mathrm{MPa}$ & 10 & 1200 & 1200 & 5 & 5 \\
\hline
\end{tabular}


Table 3 Latent hardening parameters used in the simulation

\begin{tabular}{lcccc}
\hline & Basal & Prismatic & Pyramidal $<\mathrm{c}+\mathrm{a}>$ & Twinning \\
Basal & 0.2 & 0.5 & 0.5 & 0.25 \\
Prismatic & 0.2 & 0.2 & 0.5 & 0.25 \\
Pyramidal $<\mathrm{c}+\mathrm{a}>$ & 1.0 & 1.0 & 0.2 & 2 \\
Twinning & 0.25 & 0.25 & 0.25 & 0.25 \\
\hline
\end{tabular}



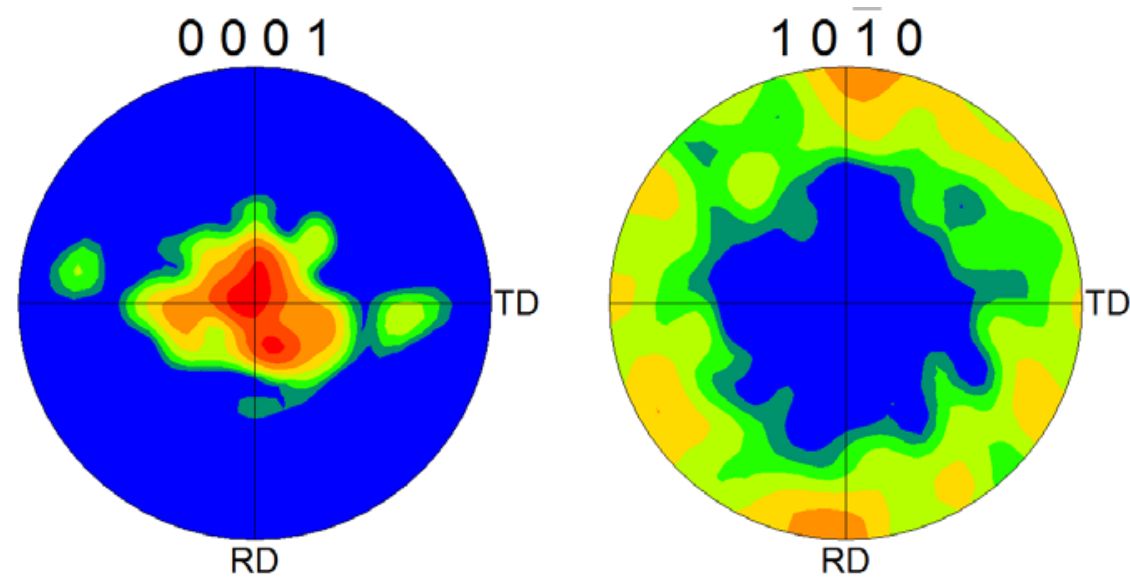

$\max =7.801$
6.000
4.193
2.930
2.048
1.431
1.000
0.699

Fig. 1 Initial pole figures of the material used in experiment. 

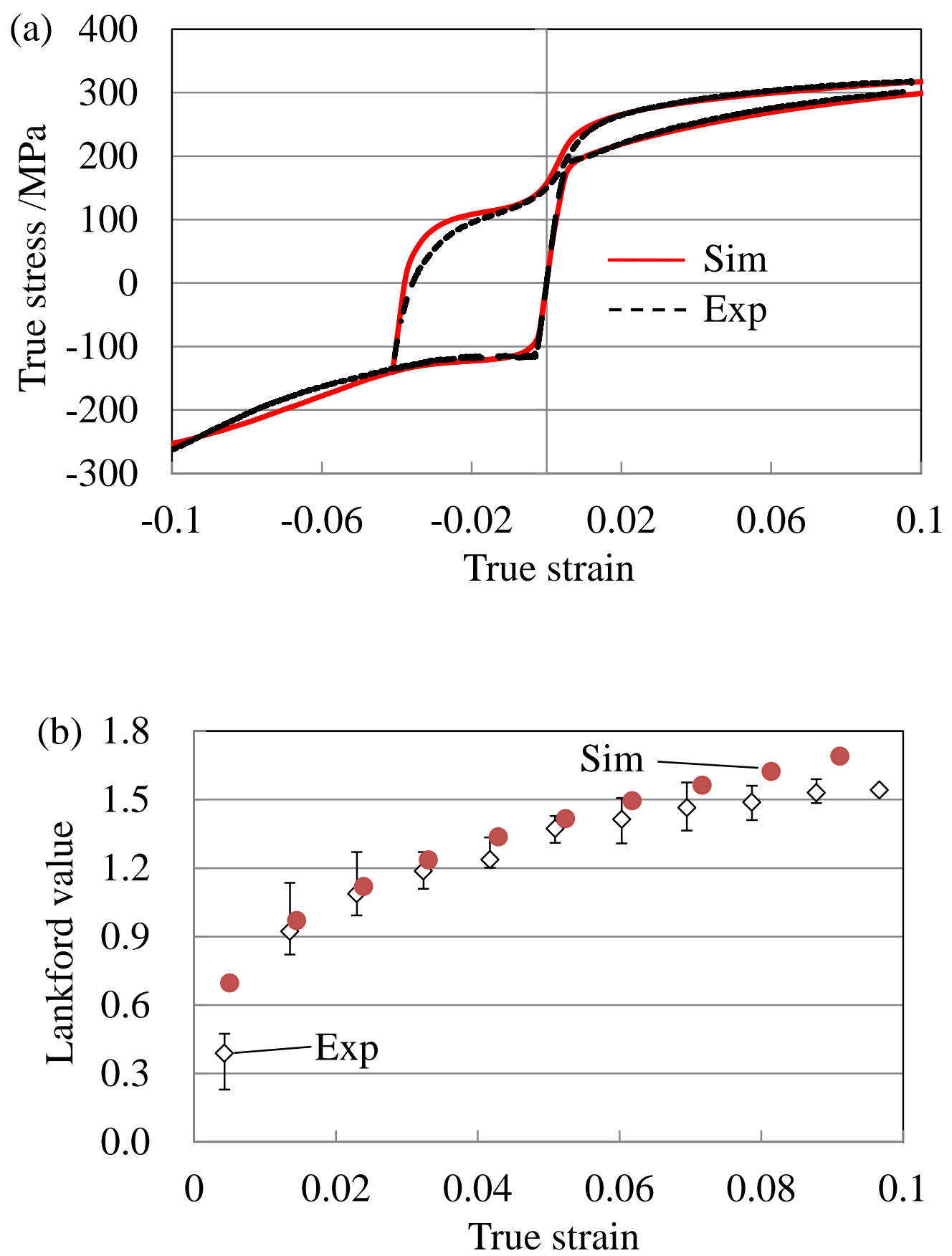

Fig. 2 Experimental and simulation results of (a) the stress-strain curves under tension, compression, and reverse loading, and (b) evolution of the Lankford value. 

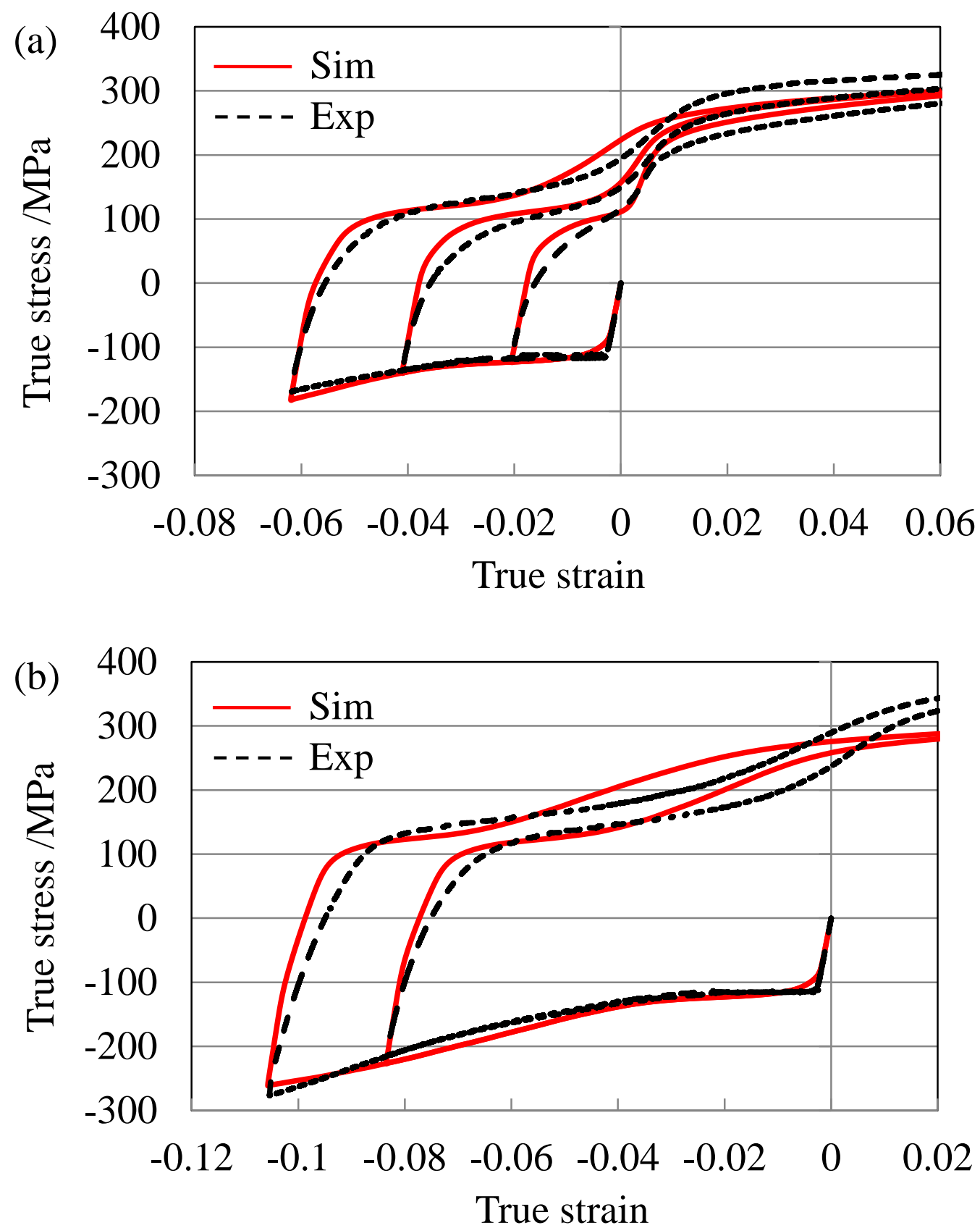

Fig. 3 Stress-strain curves under reverse loading with different compressive strains. Results are shown for the compressive strains of (a) $2 \%, 4 \%$, and $6 \%$, and (b) $8 \%$ and $10 \%$. 


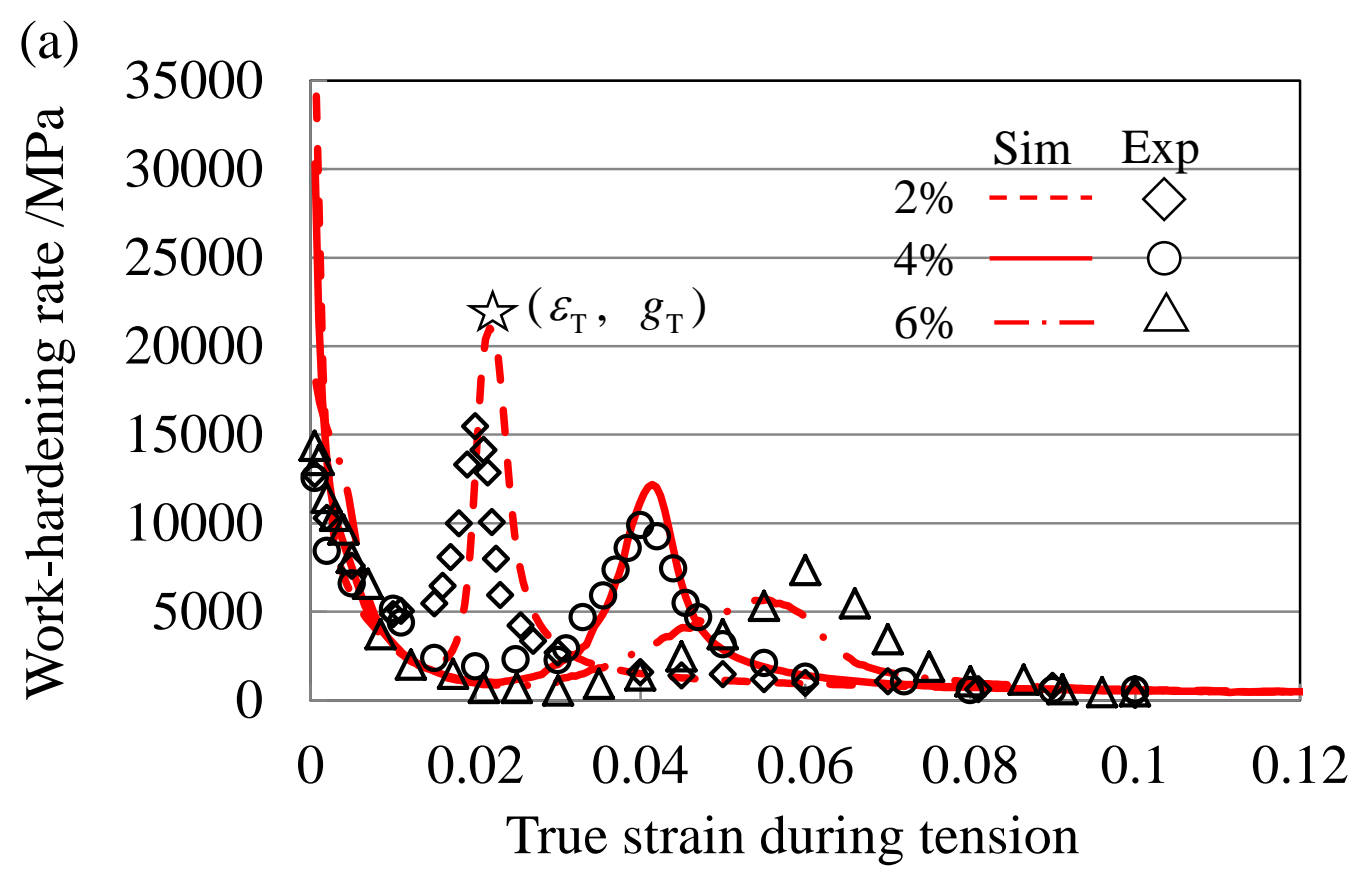

(b)

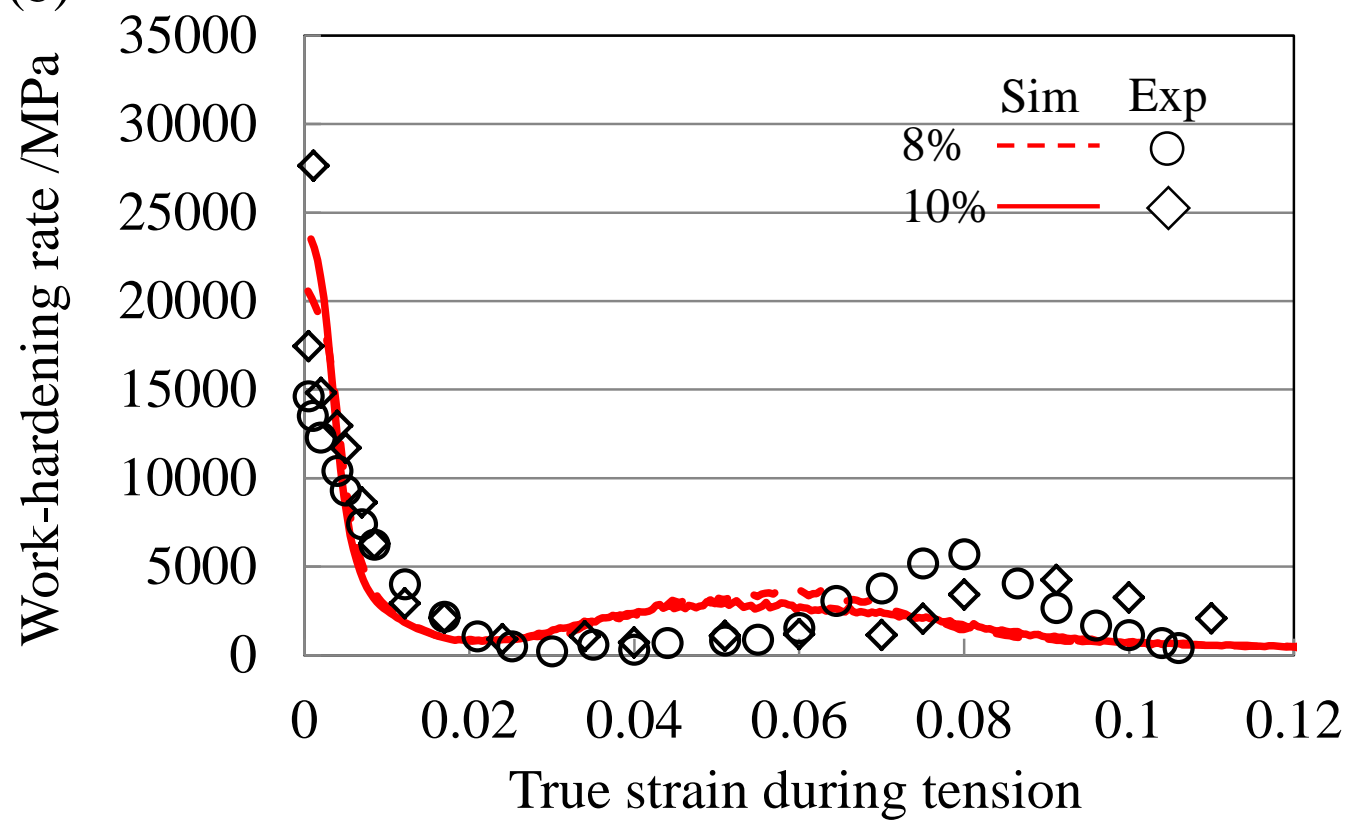

Fig. 4 Evolution of the work-hardening rate during subsequent tension. Results are shown for the compressive strains of (a) $2 \%$, $4 \%$, and $6 \%$, and (b) $8 \%$ and $10 \%$. The $\varepsilon_{\mathrm{T}}$ and $g_{\mathrm{T}}$ values are defined as the point where the peak gradient occurs, and denoted by the star mark. 


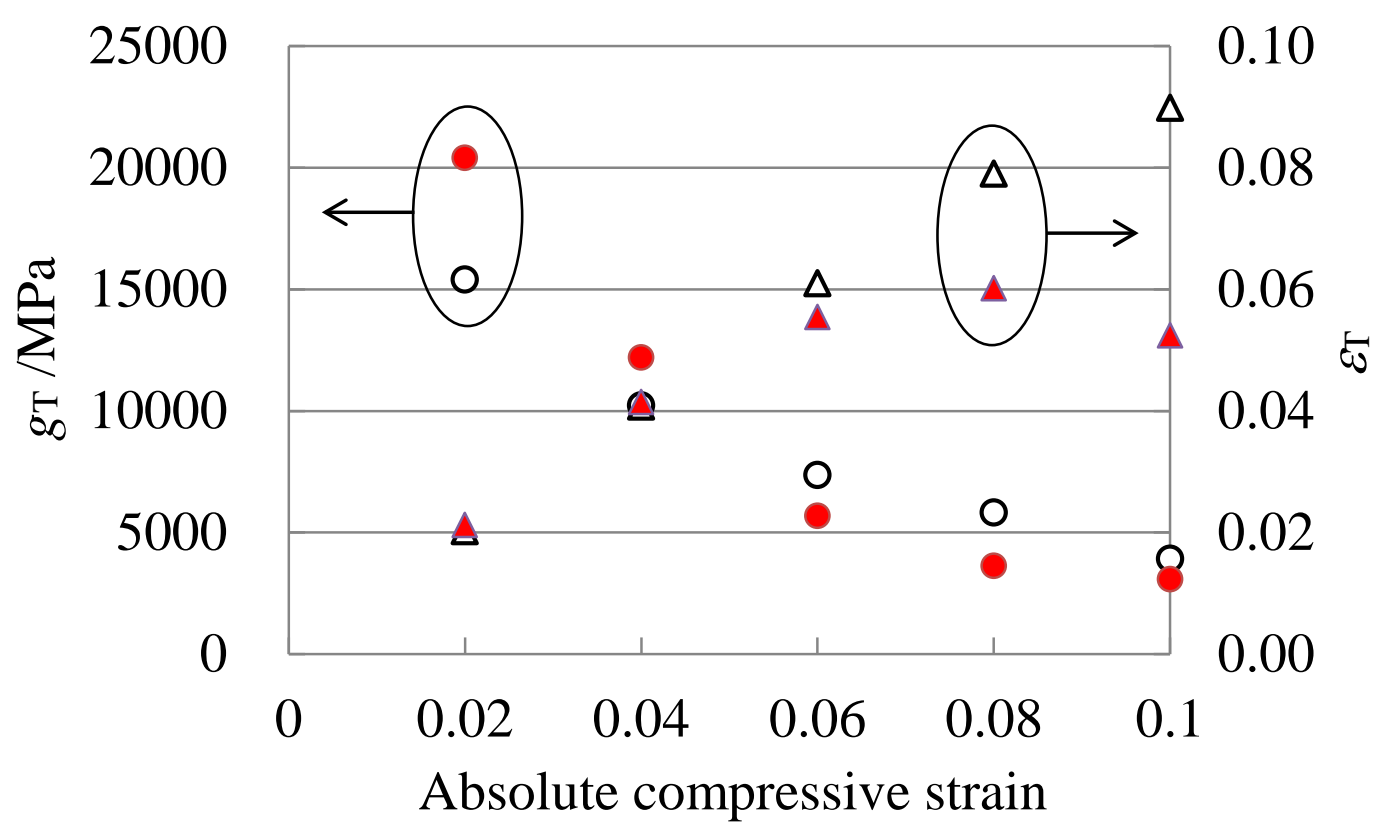

Fig. 5 Variations of $g_{\mathrm{T}}$ and $\varepsilon_{\mathrm{T}}$ as functions of absolute compressive strain measured in Fig. 4. Circles and triangles denote $g_{\mathrm{T}}$ and $\varepsilon_{\mathrm{T}}$, respectively. Solid and open marks denote the simulation and experimental results, respectively. 

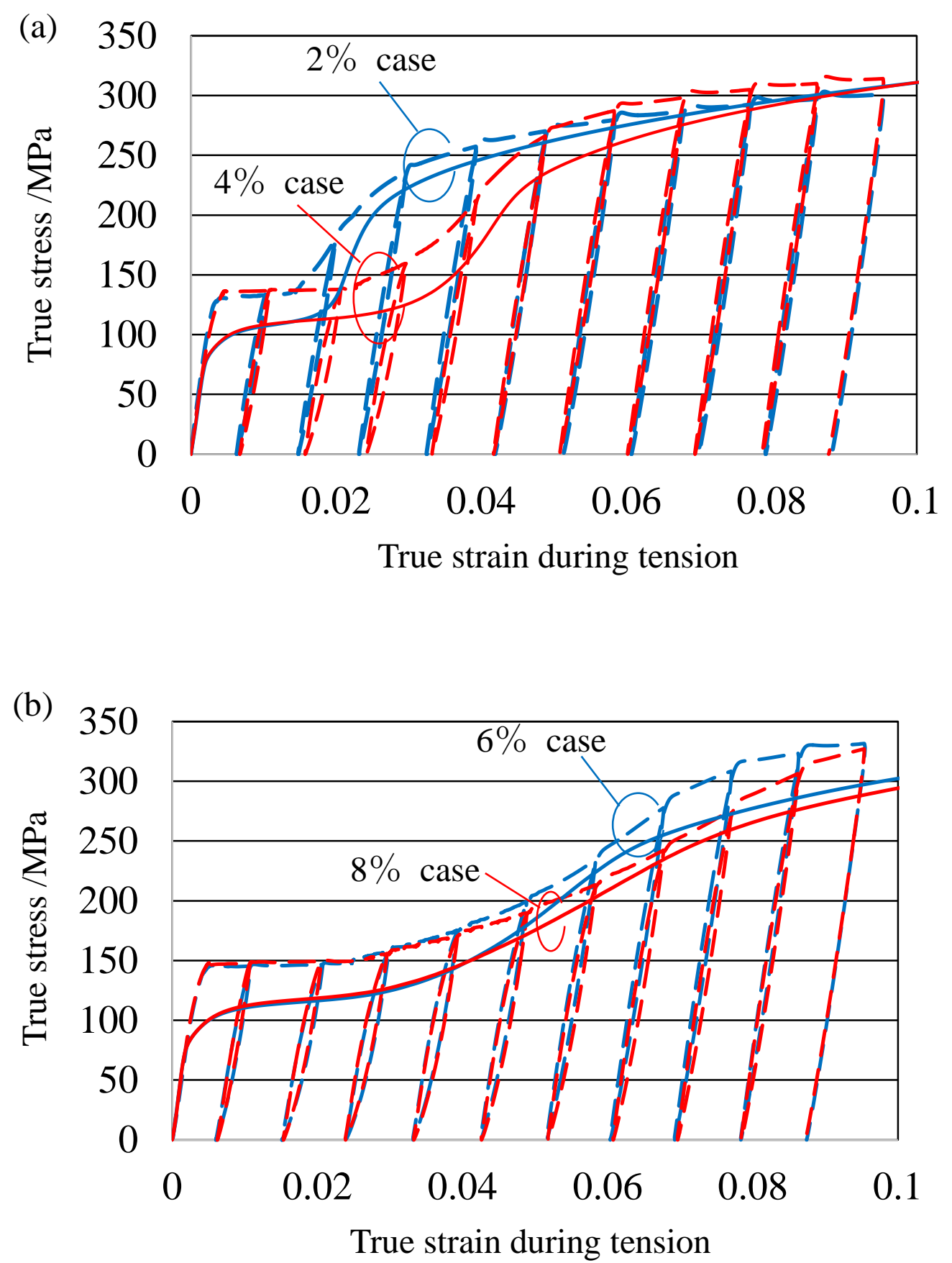

Fig. 6 Stress-strain curves after stress reversal obtained using non-annealed and annealed sheets. The compressive strains are (a) $2 \%$ and $4 \%$, and (b) $6 \%$ and $8 \%$. Solid and broken lines denote simulation and experimental results, respectively. 


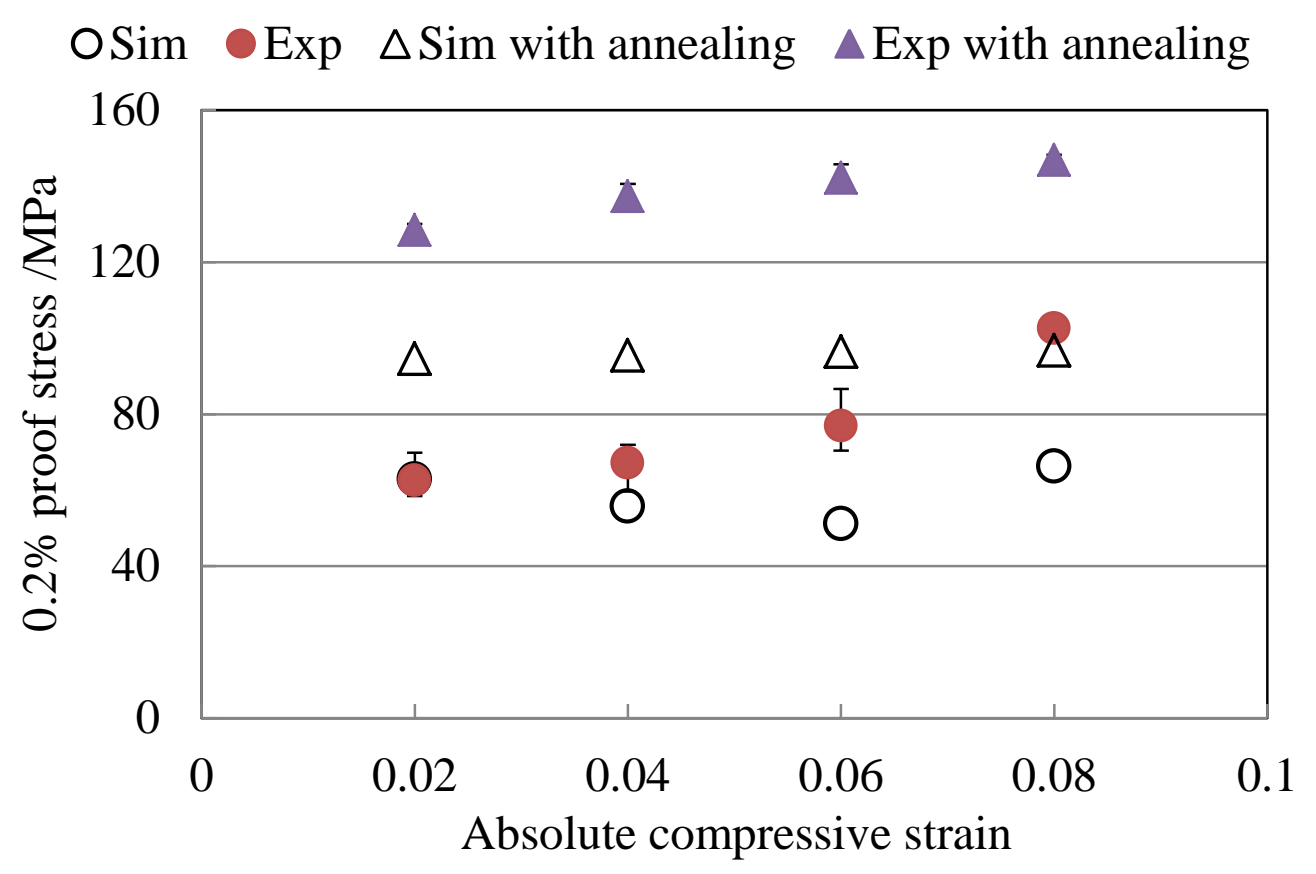

Fig. 7 Relationship between the $0.2 \%$ proof stress during subsequent tension and absolute compressive strain. 


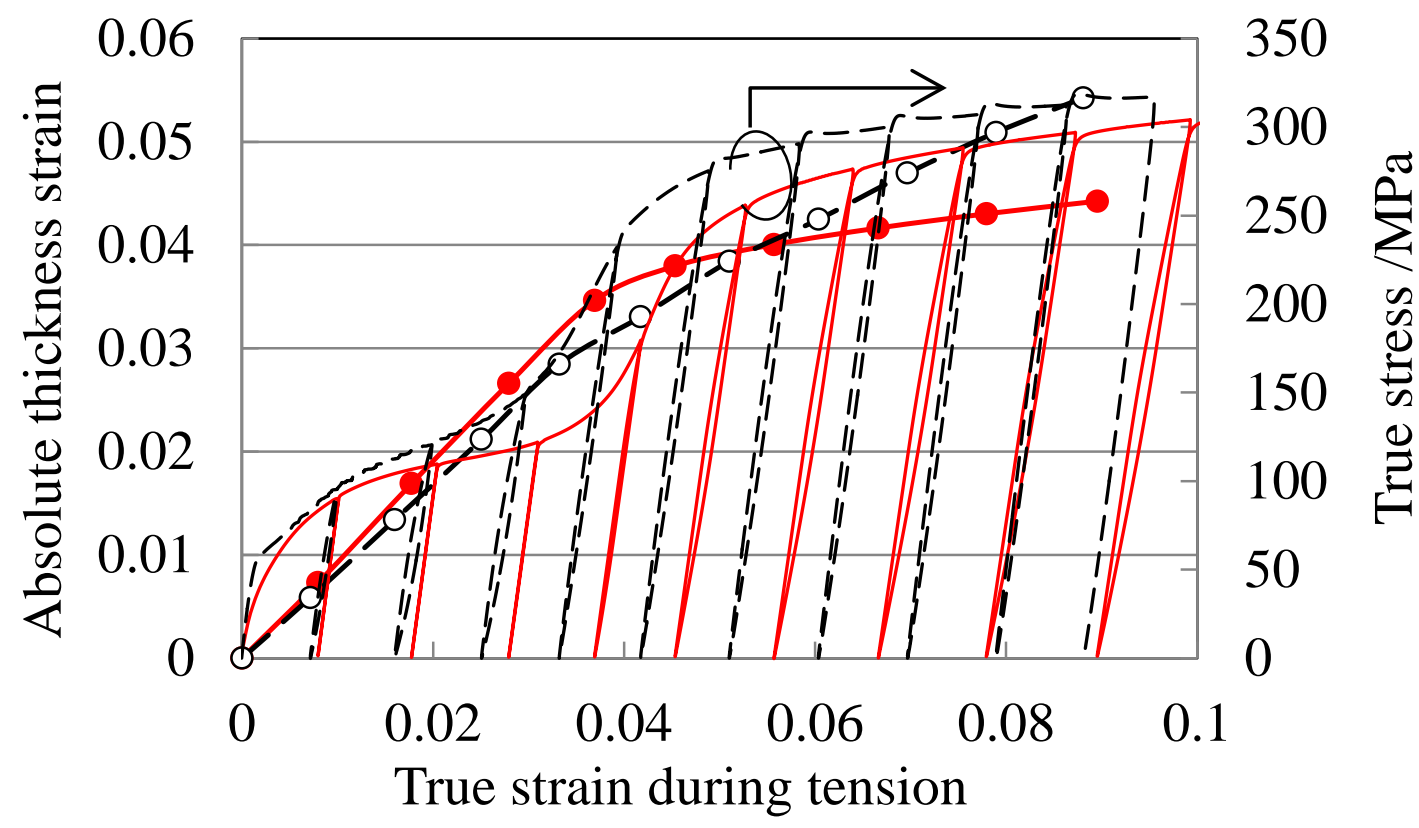

Fig. 8 Evolution of the absolute thickness strain during tension. The compressive strain was $4 \%$. Solid and broken lines denote the simulation and experimental results, respectively. 
(a)

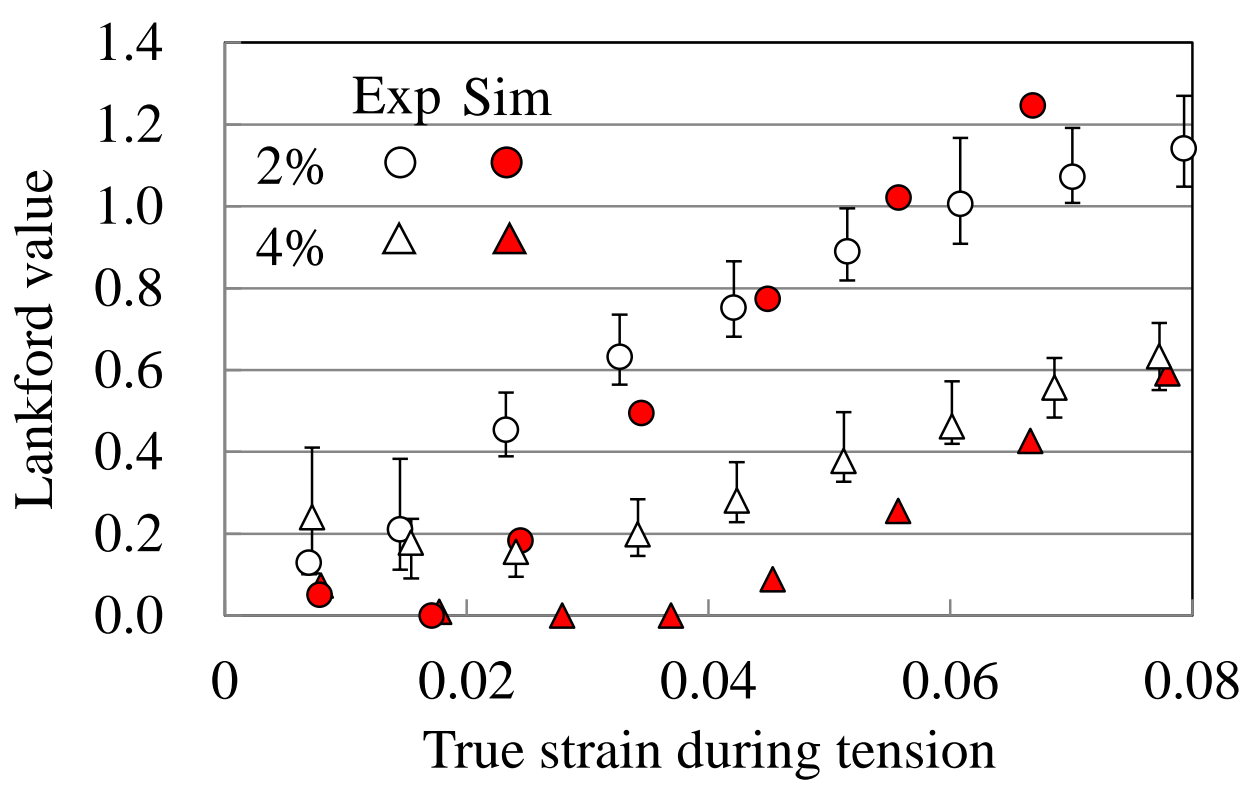

(b)
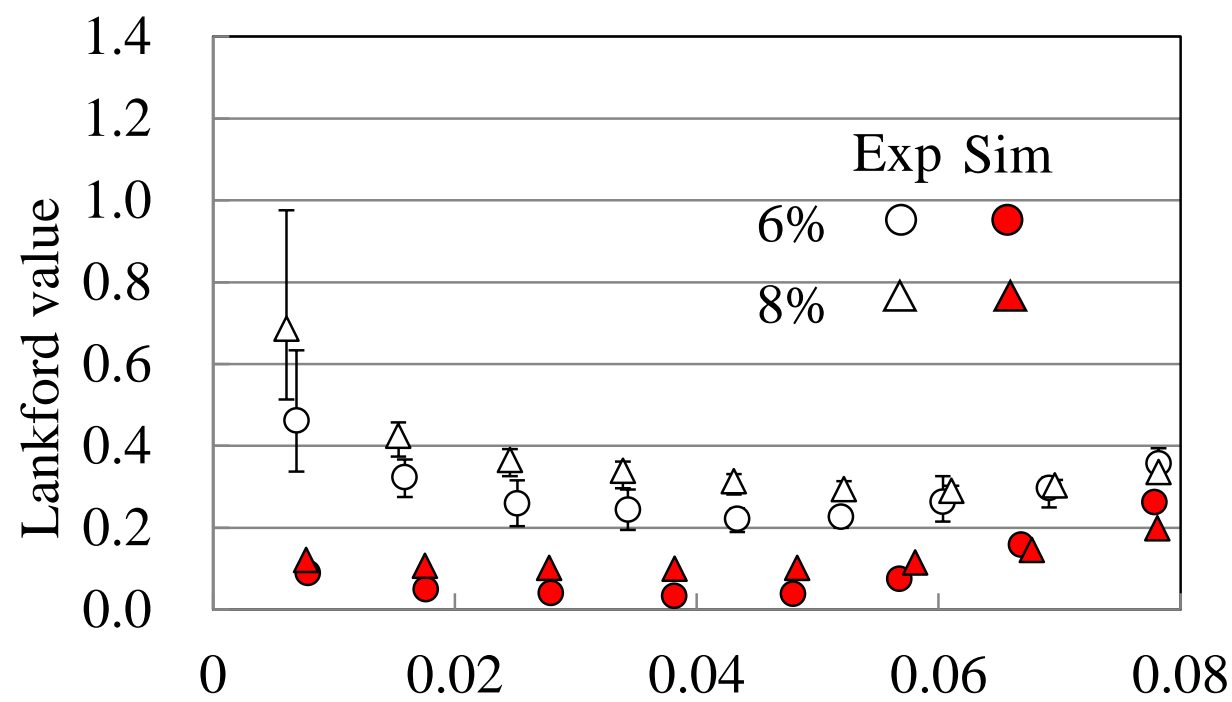

True strain during tension

Fig. 9 Evolution of the Lankford value during subsequent tension. Results are shown for the compressive strains of (a) $2 \%$ and $4 \%$ and (c) $6 \%$ and $8 \%$. 

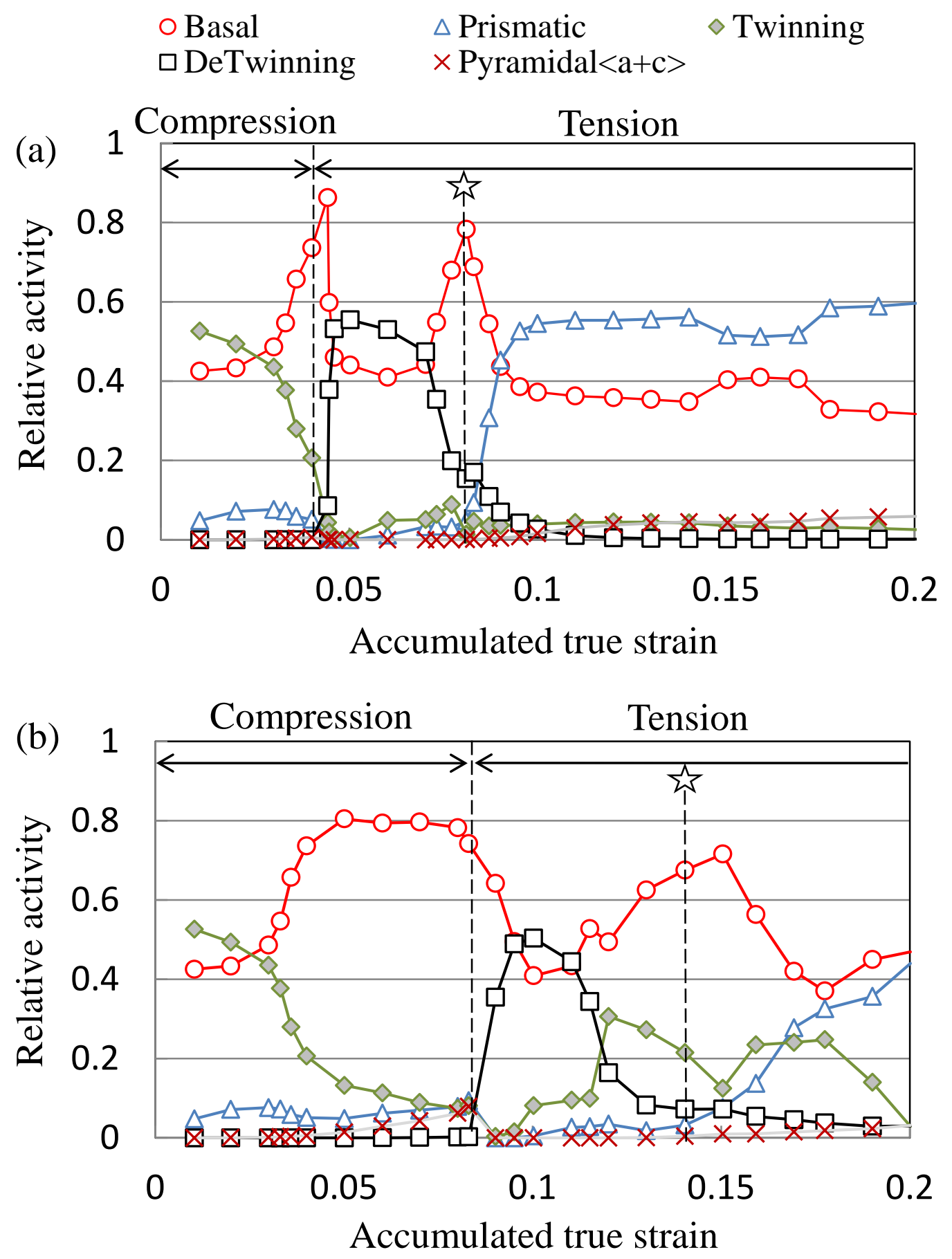

Fig. 10 Evolution of the relative activities during reverse loading with compressive strains of (a) 4\% and (b) $8 \%$. The peak gradient occurs at strains denoted by star marks. 
(a)

(b)

(c)

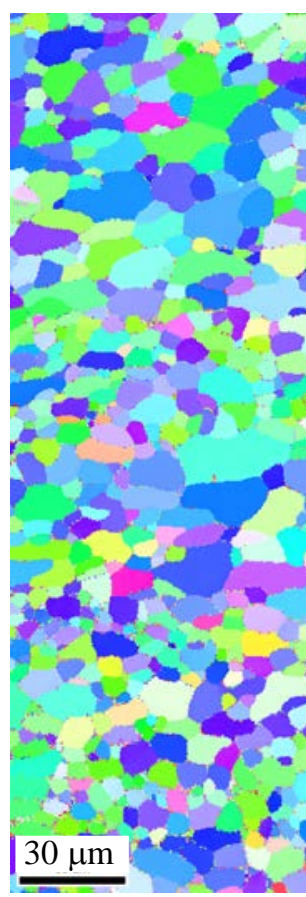

(b)

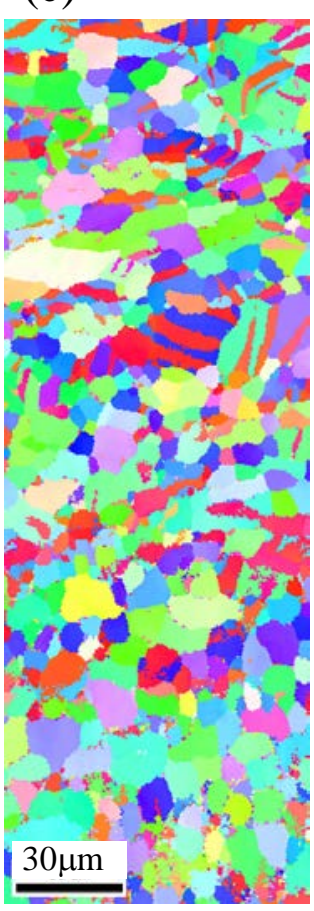

(d)
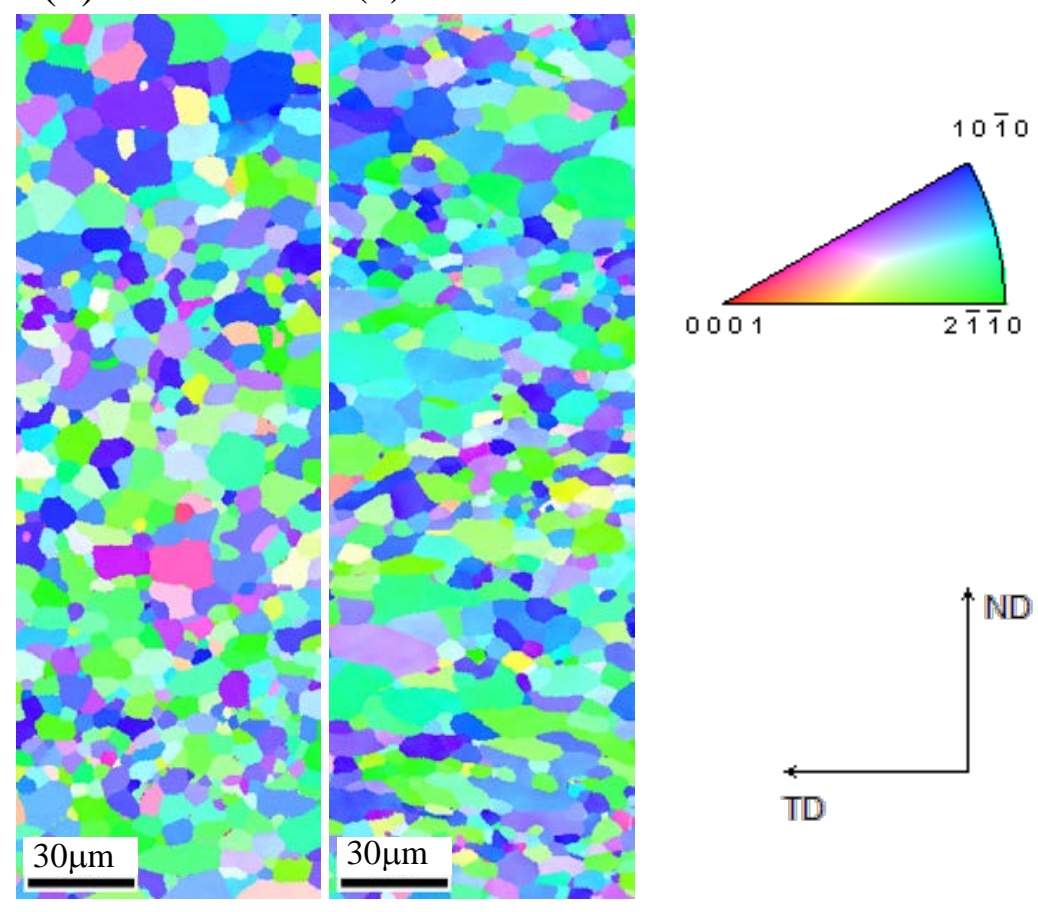

Fig. 11 IPF maps of (a) initial sheet and pre-compressed sheets with compressive strain of $4 \%$ measured at accumulated strains of approximately (b) 4\%, (c) 5\%, (d) $7 \%$, and (e) 10\%. The result of initial sheet corresponds to the pole figure shown in Fig. 1. 
(a)

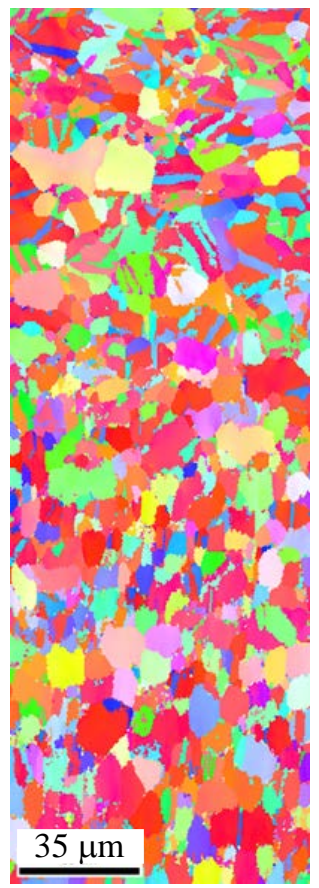

(b)

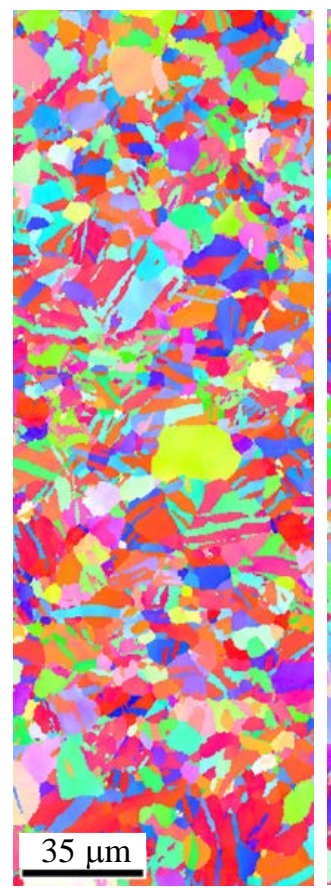

(c)

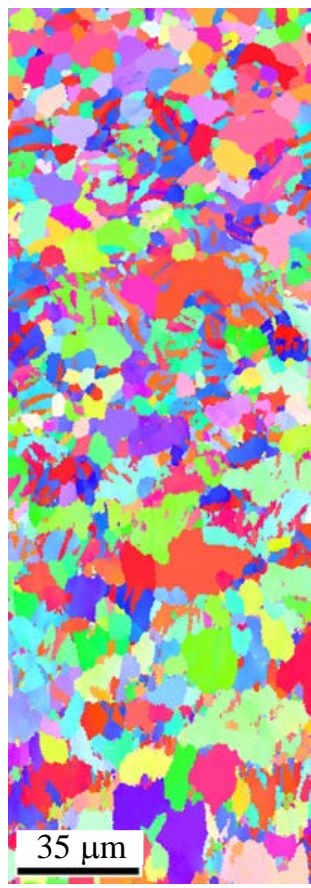

(d)

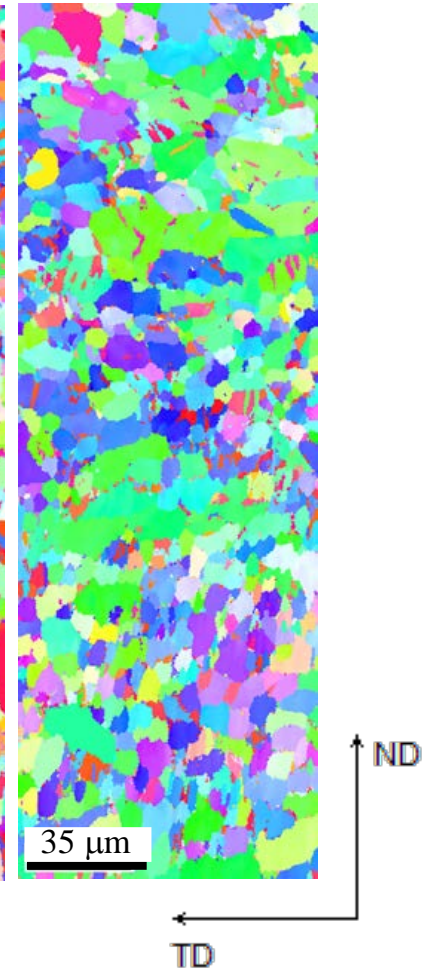

Fig. 12 IPF maps measured on a pre-compressed sheet with compressive strain of $8 \%$. Results are measured at accumulated strains of approximately (a) $10 \%$, (b) $11 \%$, (c) $13 \%$, and (d) $15 \%$. 


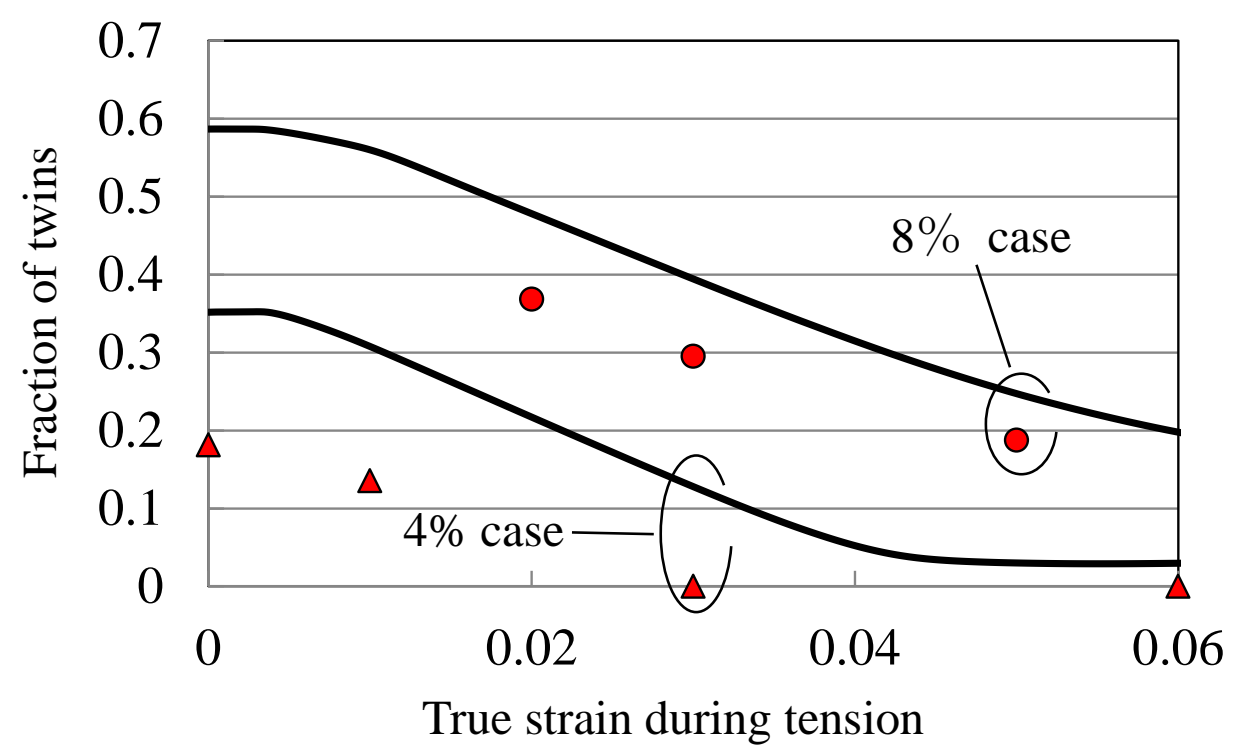

Fig. 13 Evolution of the twin fraction. Solid lines and symbols denote the simulation and experimental results, respectively. 

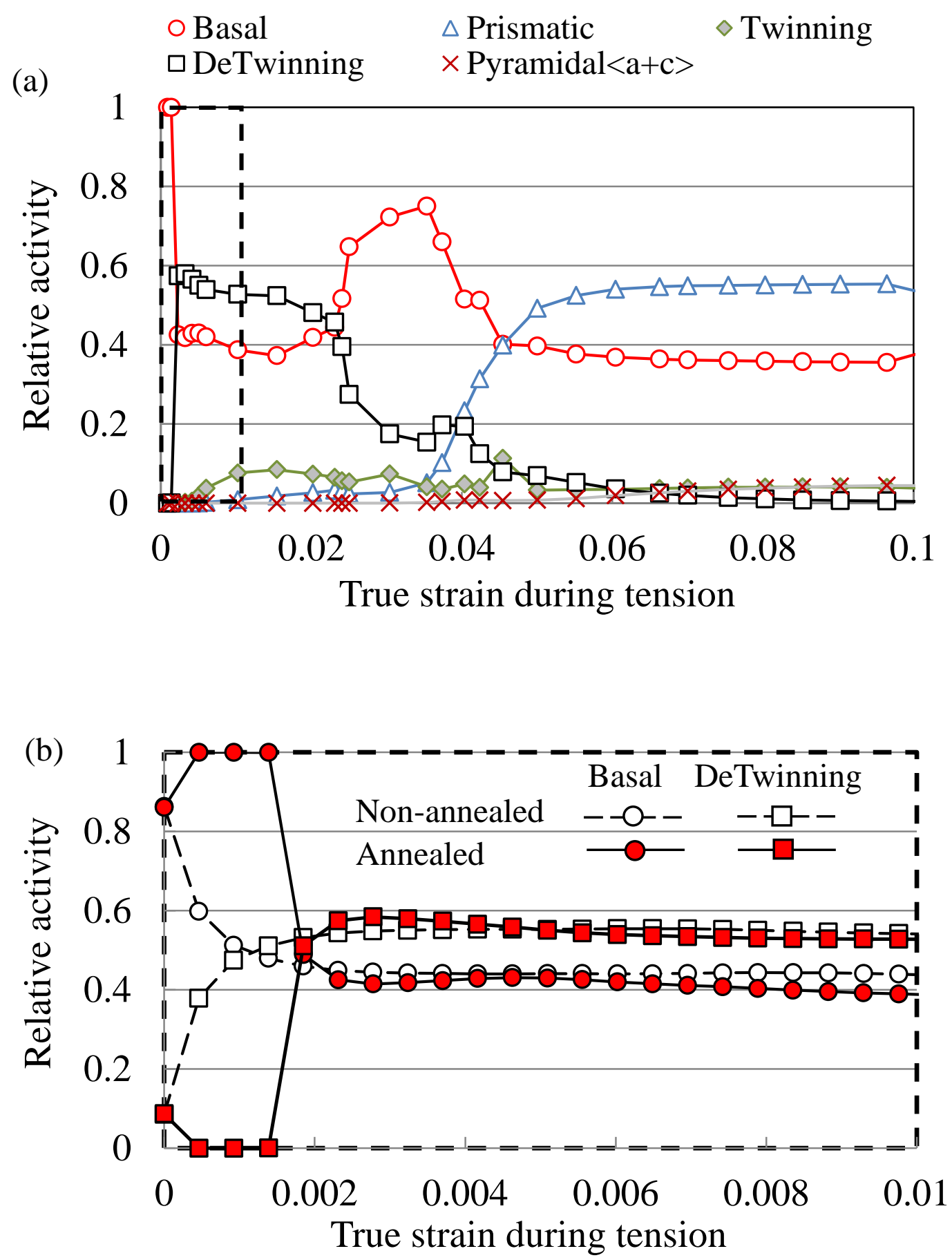

Fig. 14 Evolution of relative activities during subsequent tension for the annealed sheet with compressive strain of 4\%. Strain ranges are (a) from $0 \%$ to $10 \%$ and (b) from $0 \%$ to $1 \%$. In (b), only the results of basal and detwinning are shown, and results of the non-annealed sheet are also shown. 
(a)

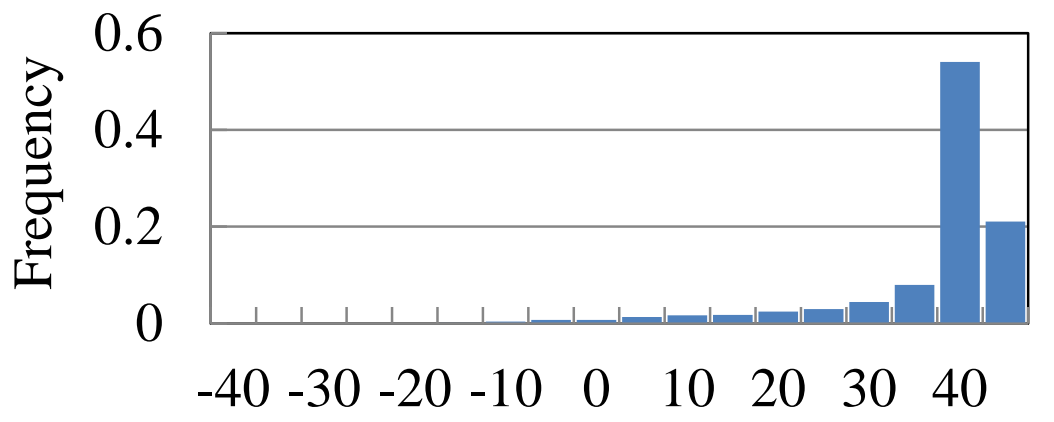

Resolved shear stress /MPa

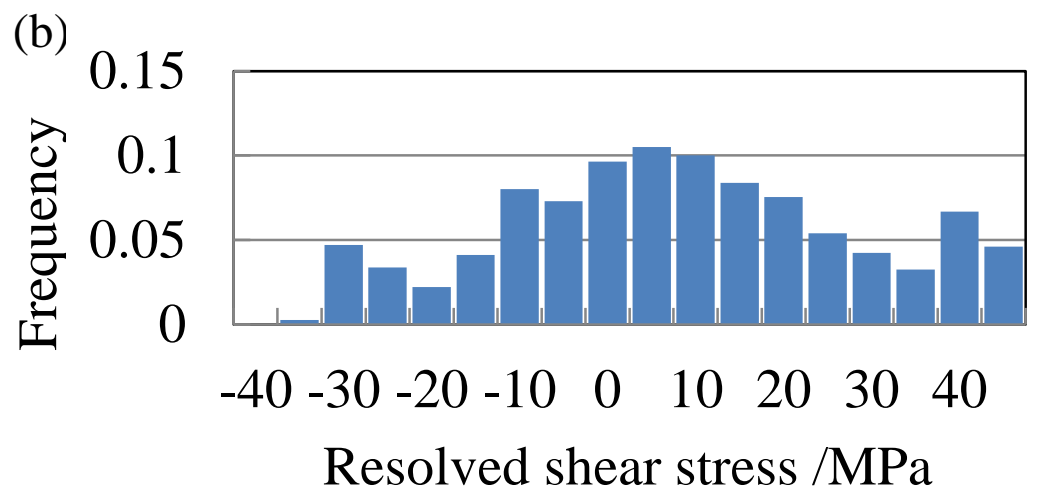

Fig. 15 Histograms of the resolved shear stress of active twinning systems. Results were measured at a compressive strain of $4 \%$ (a) before unloading and (b) after unloading. 


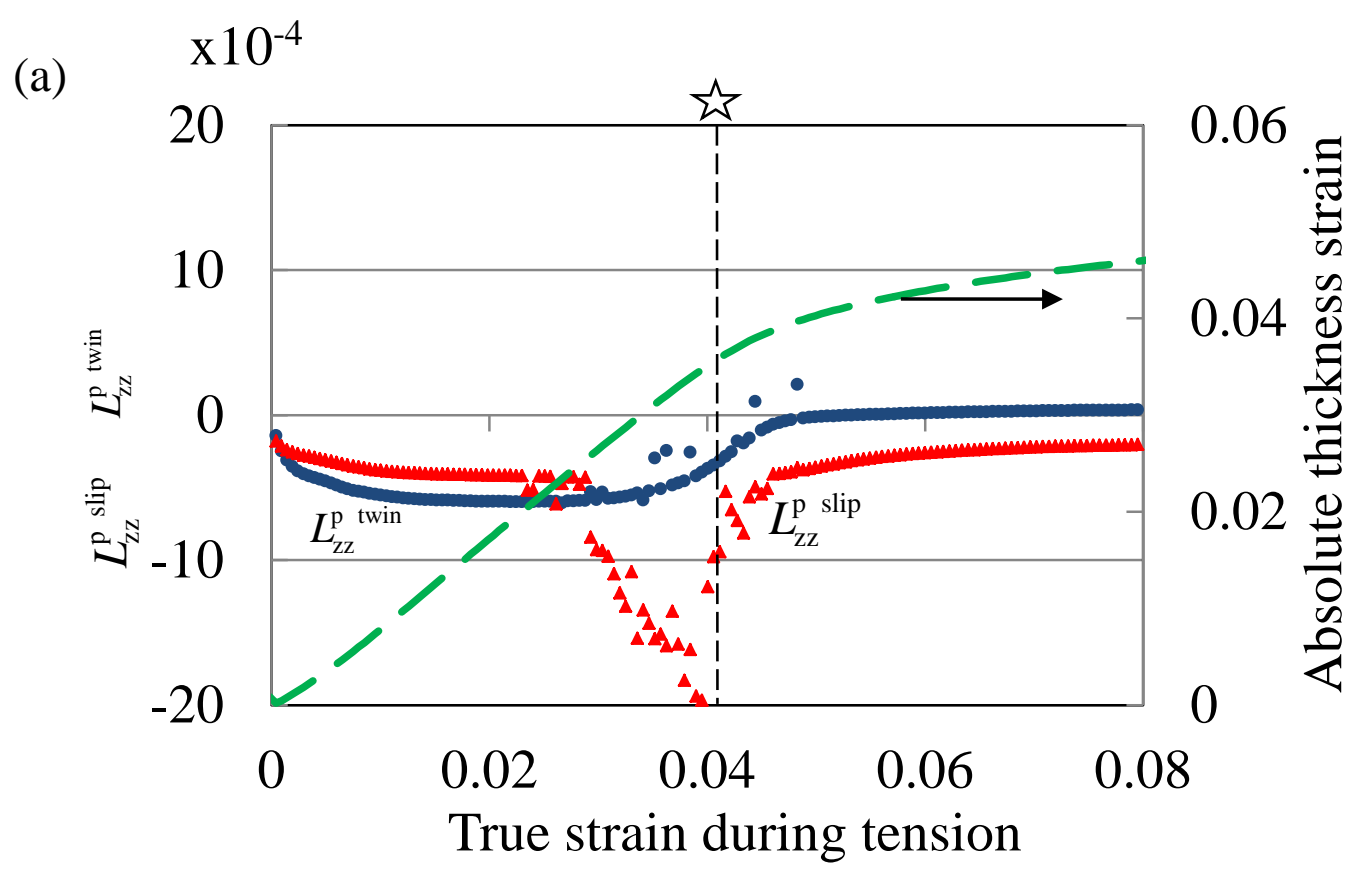

(b)

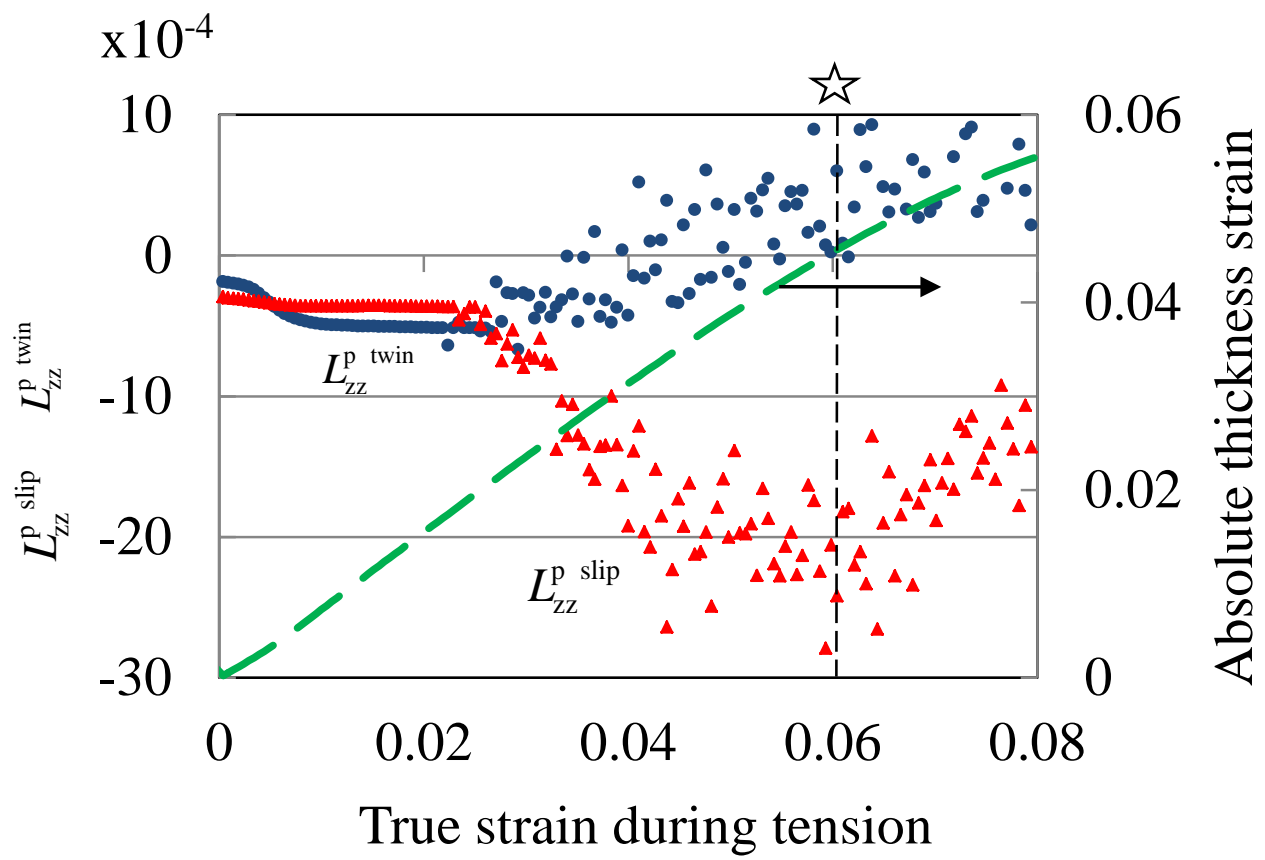

Fig. 16 Evolution of $L_{\mathrm{zz}}^{\mathrm{p} \text { twin }}$ and $L_{\mathrm{zz}}^{\mathrm{p} \text { slip }}$ for compressive strains of (a) 4\% and (b) 8\%. Circles and triangles denote $L_{z z}^{\text {p twin }}$ and $L_{z z}^{\text {p slip }}$, respectively, and the broken line is the absolute thickness strain. 